\title{
A COMPARISON OF LATENT HEAT FLUXES OVER GLOBAL OCEANS FOR FOUR FLUX PRODUCTS
}

\author{
Shu-Hsien Chou, Eric Nelkin, Joe Ardizzone, and Robert M. Atlas
}

\author{
Popular Summary
}

To improve our understanding of global energy and water cycle variability, and to improve model simulations of climate variations, it is vital to have accurate latent heat fluxes (LHF) over global oceans. Monthly LHF, $10-\mathrm{m}$ wind speed $\left(\mathrm{U}_{10 \mathrm{~m}}\right), 10-\mathrm{m}$ specific humidity $\left(\mathrm{Q}_{10 \mathrm{~m}}\right)$, and sea-air humidity difference $\left(\mathrm{Q}_{\mathrm{s}}-\mathrm{Q}_{10 \mathrm{~m}}\right)$ of GSSTF2 (version 2 Goddard Satellite-based Surface Turbulent Fluxes) over global oceans during 1992-93 are compared with those of HOAPS (Hamburg Ocean Atmosphere Parameters and Fluxes from Satellite Data), NCEP (NCEP/NCAR reanalysis), and da Silva (da Silva et al.). The mean differences, standard deviations of differences, and temporal correlation of these monthly variables over global oceans during 1992-93 between GSSTF2 and each of the three datasets are analyzed. The large-scale patterns of the $2 \mathrm{yr}$-mean fields for these variables are similar among these four datasets, but significant quantitative differences are found.

The temporal correlation is higher in the northern extratropics than in the south for all variables, with the contrast being especially large for da Silva as a result of more missing ship data in the south. The da Silva has extremely low temporal correlation and large differences with GSSTF2 for all variables in the southern extratropics, indicating that da Silva hardly produces a realistic variability in these variables. The NCEP has extremely low temporal correlation (0.27) and large spatial variations of differences with GSSTF2 for $\mathrm{Q}_{\mathrm{s}}-\mathrm{Q}_{10 \mathrm{~m}}$ in the tropics, which causes the low correlation for LHF. Over the tropics, the HOAPS LHF is significantly smaller than GSSTF2 by $31 \%\left(37 \mathrm{~W} \mathrm{~m}^{-2}\right)$, whereas the other two datasets are comparable to GSSTF2. This is because the HOAPS has systematically smaller LHF than GSSTF2 in space, while the other two datasets have very large spatial variations of large positive and negative LHF differences with GSSTF2 to cancel and to produce smaller regional-mean differences. Our analyses suggest that the GSSTF2 latent heat flux, surface air humidity, and winds are likely to be more realistic than the other three flux datasets examined, although those of GSSTF2 are still subject to regional biases. 
A Comparison of Latent Heat Fluxes over Global Oceans for Four Flux Products

\author{
Shu-Hsien Chou \\ Laboratory for Atmospheres \\ NASA Goddard Space Flight Center \\ Greenbelt, Maryland \\ Eric Nelkin \\ Science Systems \& Applications, Inc. \\ Lanham, Maryland \\ Joe Ardizzone \\ Science Applications International Corporation \\ Laurel, Maryland \\ Robert M. Atlas \\ Laboratory for Atmospheres \\ NASA Goddard Space Flight Center \\ Greenbelt, Maryland
}

Journal of Climate

November 5, 2003

Corresponding author: Dr. Shu-Hsien Chou, Code 912, Laboratory for Atmospheres, NASA Goddard Space Flight Center, Greenbelt, MD 20771.

E-mail: Shu-Hsien.Chou-1@nasa.gov 


\begin{abstract}
Monthly latent heat fluxes (LHF), 10-m wind speed $\left(\mathrm{U}_{10 \mathrm{~m}}\right), 10-\mathrm{m}$ specific humidity $\left(\mathrm{Q}_{10 \mathrm{~m}}\right)$, and sea-air humidity difference $\left(\mathrm{Q}_{\mathrm{s}}-\mathrm{Q}_{10 \mathrm{~m}}\right)$ of GSSTF2 (version 2 Goddard Satellite-based Surface Turbulent Fluxes) over global oceans during 1992-93 are compared with those of HOAPS (Hamburg Ocean Atmosphere Parameters and Fluxes from Satellite Data), NCEP (NCEP/NCAR reanalysis), and da Silva (da Silva et al.). The mean differences, standard deviations of differences, and temporal correlation of these monthly variables over global oceans during 1992-93 between GSSTF2 and each of the three datasets are analyzed. The large-scale patterns of the 2yr-mean fields for these variables are similar among these four datasets, but significant quantitative differences are found.

The temporal correlation is higher in the northern extratropics than in the south for all variables, with the contrast being especially large for da Silva as a result of more missing ship data in the south. The da Silva has extremely low temporal correlation and large differences with GSSTF2 for all variables in the southern extratropics, indicating that da Silva hardly produces a realistic variability in these variables. The NCEP has extremely low temporal correlation (0.27) and large spatial variations of differences with GSSTF2 for $Q_{s}-Q_{10 m}$ in the tropics, which causes the low correlation for LHF. Over the tropics, the HOAPS LHF is significantly smaller than GSSTF2 by $\sim 31 \%\left(37 \mathrm{~W} \mathrm{~m}^{-2}\right)$, whereas the other two datasets are comparable to GSSTF2. This is because the HOAPS has systematically smaller LHF than GSSTF2 in space, while the other two datasets have very large spatial variations of large positive and negative LHF differences with GSSTF2 to cancel and to produce smaller regional-mean differences. Our analyses suggest that the GSSTF2 latent heat flux, surface air humidity, and winds are likely to be more realistic than the other three flux datasets examined, although those of GSSTF2 are still subject to regional biases.
\end{abstract}




\section{Introduction}

Information on the freshwater (precipitation-evaporation), heat, and momentum fluxes at the sea surface is essential in understanding the interactions between the atmosphere and oceans, as well as global energy and water cycle variability, and in improving model simulations of climate variations. To predict or understand the sea surface temperature (SST) change that crucially affects the global climate, it is paramount that we know the variability of net surface heat flux. The spatial variations of seasonal and interannual variability of net surface heat flux are dominated by the variability of latent heat flux (LHF). This is because the spatial variation of LHF is significantly larger than that of shortwave radiative flux, although the magnitude of solar heating is larger than that of evaporative cooling (e.g., da Silva et al. 1994; Josey et al. 1999; Chou et al. 2003b). Thus it is important to have a reliable long-term global dataset of LHF.

Surface measurements of LHF and other fluxes are scarce in both space and time. The Comprehensive Ocean-Atmosphere Data Set (COADS) has collected the most complete surface marine observations since 1854, mainly from merchant ships (Woodruff et al. 1993). However, the COADS-based fluxes have serious spatial and temporal sampling problems (measurements over the ship lanes with fair weather bias), together with measurement uncertainty (e.g., da Silva et al. 1994; Josey et al. 1999; Wang and McPhaden 2001). Therefore, it is desirable that long-term global datasets of these fluxes be derived either from satellite observations or general circulation models (GCM). The World Climate Research Program (WCRP)/Global Energy and Water Experiment (GEWEX) Radiation Panel has established a SEA surface turbulent FLUX project, called SEAFLUX (Curry et al. 2003). The goal is to produce accurate high-resolution satellitebased datasets of surface turbulent fluxes (momentum, latent heat, and sensible heat) over global oceans.

Currently, there are several datasets of global ocean LHF available, which are based on the surface air humidity and winds derived from the Special Sensor Microwave/Imager (SSM/I) on board a series of the Defense Meteorological Satellite Program (DMSP) spacecraft. The Hamburg Ocean Atmosphere Parameters and Fluxes from Satellite Data (HOAPS; Graßl et al. 2000) has daily and monthly LHF over global oceans with $0.5^{\circ}$ spatial resolution for the period July 
1987-December 1998, based on the method of Schulz et al. (1997). The Goddard Satellite-based Surface Turbulent Fluxes (GSSTF) has two versions of global ocean LHF derived from the SSM/I radiances. The version 1 (GSSTF1) has daily and monthly fields for July 1987-December 1994 with a spatial resolution of $2.0^{\circ} \times 2.5^{\circ}$ lat-lon (Chou et al. 1997, 2000). The version 2 (GSSTF2) has daily and monthly fields for July 1987-December 2000 with $1^{\circ}$ resolution (Chou et al. 2003). The Japanese Ocean Flux dataset with Use of Remote sensing Observations (J-OFURO) has monthly turbulent heat fluxes over global oceans with $1^{\circ}$ resolution for 1991-95 (Kubota et al., 2002). The J-OFURO has been further extended to the period 1992-2000 with 3 days temporal resolution. These flux datasets and others have been distributed to the SEAFLUX web site for intercomparison studies (Curry et al. 2003).

The LHF is derived using various bulk flux algorithms from surface winds, surface air humidity and temperature, and SST, all of which may have a large uncertainty in the reanalyses, satellite retrievals, and COADS. There is no "ground truth" for the global LHF fields; thus it is important to conduct intercomparison studies to assess the sources of errors for various global LHF products. The studies can identify the strengths and weaknesses of various LHF products, and provide important information for improving atmospheric GCMs and satellite retrievals. As the NCEP/NCAR reanalysis (Kalnay et al. 1996, referred to as NCEP) and da Silva et al. (1994, referred to as da Silva) have been widely used for various climate studies, it is important to include them for the comparison. Kubota et al. (2003) compared the LHF of GSSTF1, HOAPS, JOFURO, NCEP, and the ECMWF (the European Centre for Medium-Range Weather Forecasts) analysis for 1992-94, as well as the LHF of da Silva for 1992-93, over the global oceans. They found that the large-scale patterns of LHF are generally similar but with significant quantitative differences among various products.

Chou et al. (2003) compared the zonal averages of the GSSTF2 LHF and input parameters over global oceans with those of GSSTF1, HOAPS, NCEP, and da Silva for the 2yr-mean of 1992-93. They found that these datasets had significant differences in these parameters with GSSTF2, except GSSTF1. For the GSSTF1, the differences with GSSTF2 were generally negligibly small for the input parameters, but not for LHF. The difference in LHF was mainly caused by a different von 
Karman constant for humidity between GSSTF1 $(0.45)$ and GSSTF2 (0.40). Averaging the LHF over the oceans within $60^{\circ} \mathrm{S}-60^{\circ} \mathrm{N}$, the GSSTF 1 was $12.7 \mathrm{~W} \mathrm{~m}^{-2}$ larger $(\sim 12 \%$ of the global averaged LHF of GSSTF2) than GSSTF2. The purpose of this paper is to present a detailed comparison study of the GSSTF2 LHF and input parameters with those of HOAPS, NCEP and da Silva over global oceans during 1992-93. Section 2 describes the data sources used in this study. Section 3 briefly discusses the method for deriving GSSTF2 LHF and retrieval accuracy. Section 4 presents the mean differences, standard deviations of differences, and temporal correlation of monthly input parameters for LHF (10-m wind speeds, 10-m specific humidity, and sea-air humidity differences) over global oceans during 1992-93 between GSSTF2 and each of the three datasets. The same analyses for LHF are discussed in section 5. Concluding remarks are given in section 6.

\section{Data sources}

The basic data used in this study are $1^{\circ} \times 1^{\circ}$ lat-lon monthly-mean latent heat fluxes, $10-\mathrm{m}$ wind speed $\left(\mathrm{U}_{10 \mathrm{~m}}\right)$, 10-m specific humidity $\left(\mathrm{Q}_{10 \mathrm{~m}}\right)$, and sea-air humidity difference $\left(\mathrm{Q}_{\mathrm{s}}-\mathrm{Q}_{10 \mathrm{~m}}\right)$ over global oceans for the period 1992-93 taken from GSSTF2, HOAPS, NCEP, and da Silva. For proper comparison, the 2-m specific humidity of NCEP, and 20-m wind speed and 20-m specific humidity of da Silva are adjusted to the10-m height using the GSSTF2 bulk flux model. In addition, only the space and time matched monthly mean valid data for the common period of 1992-93 are used for the comparison.

To validate GSSTF2 daily LHF and input parameters, hourly measurements of surface meteorology and LHF of nine field experiments conducted by the NOAA/Environmental Technology Laboratory (ETL) research ships over the tropical and midlatitude oceans during 1991-99 are used (Fairall et al. 1997, 2003; Brunke et al. 2003). Table 1 shows the periods and locations of these nine experiments: the Atlantic Stratocumulus Transition Experiment (ASTEX), the Coupled Ocean-Atmosphere Response Experiment (COARE), the Fronts and Atlantic Storm Track Experiment (FASTEX), the Joint Air-Sea Monsoon Interaction Experiment (JASMINE), the Kwajalein Experiment (KWAJEX), the Nauru '99 (NAURU99), the Tropical Instability Wave Experiment (TTWE), the Pan-American Climate Study in the eastern Pacific during 1999 
(PACSF99), and the buoy service in the North Pacific (MOORINGS). The experiments provide hourly (50 $\mathrm{min}$ ) covariance latent heat flux derived using the covariance or eddy correlation method. To reduce the flow distortion effects, only the data with the relative wind direction within $30^{\circ}$ of the bow are used (Yelland et al. 1998).

\section{Derivation and validation of GSSTF2 LHF}

The GSSTF2 flux model is a bulk aerodynamics algorithm based on the Monin-Obukhov similarity theory including the salinity and cool-skin effects. Chou et al. (2003) have discussed this model somewhat in detail. The daily-mean input parameters for turbulent flux calculations include SSM/I $U_{10 m}$ of Wentz (1997) and the $Q_{10 m}$, which is derived from the SSM/I precipitable water of the entire atmospheric column and the 500-m layer near the surface (Chou et al. 1995, 1997). The input parameters also include the 2-m air temperature and SST of the NCEP/NCAR reanalysis (Kalney et al. 1996). The saturation specific humidity at the sea surface $\left(Q_{s}\right)$ for computing LHF depends on the skin SST. The skin SST is generally cooler than the bulk SST with a daily mean difference of $\sim 0.2{ }^{\circ} \mathrm{C}$, but its instantaneous value relies on various bulk-skin SST difference models, surface net heat flux, and wind-induced oceanic mixing (e.g. Fairall et al. 1996b; Webster et al. 1996; Wick et al. 1996; Curry et al. 2003). In addition, the saturation vapor pressure is $~ 2 \%$ smaller for saline water than for pure water (Fairall et al. 1996a; Zeng et al. 1998). To partially compensate for the salinity and cool skin effects on LHF, the GSSTF2 flux model estimates $Q_{s}$ using the approximated formulation as $Q_{S}=0.98(0.622 \mathrm{e} / \mathrm{P})$. Here $\mathrm{e}$ is the saturation vapor pressure for pure water at the bulk SST, and P is the sea level pressure taken from the NCEP/NCAR reanalysis. The GSSTF2 neutral moisture transfer coefficient at $10-\mathrm{m}$ height is $1.05-1.22 \times 10^{-3}$ for $U_{10 \mathrm{~m}}$ of 3-18 $\mathrm{m} \mathrm{s}^{-1}$. The coefficient increases with decreasing winds for $\mathrm{U}_{10 \mathrm{~m}}$ $<3 \mathrm{~m} \mathrm{~s}^{-1}$. The GSSTF2 moisture transfer coefficient (for $U_{10 \mathrm{~m}}$ up to $\sim 18 \mathrm{~m} \mathrm{~s}^{-1}$ ) is in close agreement with those of Zeng et al. (1998), Fairall et al. (1996a), and Renfrew et al. (2002).

Chou et al. (2003) validated the GSSTF2 bulk flux model, using hourly input parameters from ship measurements of ten field experiments conducted by the NOAA/ETL. They found that the hourly LHF computed using the GSSTF2 flux model agreed very well with observations. Compared to 1913 samples of hourly observed LHF of the ten experiments, the computed hourly 
LHF had a bias of $4.5 \mathrm{~W} \mathrm{~m}^{-2}$, a standard deviation (SD) error of $19.6 \mathrm{~W} \mathrm{~m}^{-2}$, and a correlation of 0.91 , with a correlation range of $0.77-0.95$. The SD error is the standard deviation of the differences between the computed and observed. Their results suggested that the GSSTF2 flux model is generally accurate for weak and moderate winds, but slightly underestimates LHF for strong winds.

Chou et al. (2003) also validated the GSSTF2 daily turbulent fluxes and input parameters with the nine NOAA/ETL field experiments shown in Table 1 . The comparison of daily LHF and relevant input parameters between GSSTF2 and the nine field experiments are shown in Table 2 and Fig. 1. Using the GSSTF2 flux model, the GSSTF2 daily surface wind speed (U) and surface air specific humidity $\left(Q_{a}\right)$ are adjusted to the measurement heights of the ships $(\sim 14-21 \mathrm{~m})$ for proper validation. The GSSTF2 daily SST is compared with the bulk SST at the 5-cm depth measured by the ships. The comparison with five major tropical experiments with large samples (ASTEX, COARE, JASMINE, NAURU99, and KWAJEX) is also shown in Table 2 for reference.

Compared to the nine (five tropical) experiments, Fig. 1 and Table 2 show that, the GSSTF2 daily LHF has a bias of $0.8(-2.6) \mathrm{W} \mathrm{m}^{-2}$, a SD error of $35.8(29.7) \mathrm{W} \mathrm{m}^{-2}$, and a correlation of $0.83(0.80)$. The GSSTF2 daily wind speed has a bias of $0.36(0.31) \mathrm{m} \mathrm{s}^{-1}$, a SD error of 1.38 (1.07) $\mathrm{m} \mathrm{s}^{-1}$, and a correlation of $0.92(0.87)$. The GSSTF2 daily surface air specific humidity has a bias of 0.67 (1.01) $\mathrm{g} \mathrm{kg}^{-1}$, a SD error of $1.23(1.11) \mathrm{g} \mathrm{kg}^{-1}$, and a correlation of $0.97(0.85)$. The GSSTF2 daily SST has a bias of $0.04(0.02){ }^{\circ} \mathrm{C}$, a SD error of $0.51(0.30){ }^{\circ} \mathrm{C}$, and a corrlelation of 1.0 (0.99). We note that the GSSTF2 daily $\mathrm{Q}_{\mathrm{a}}$ has a positive bias of $\sim 1 \mathrm{~g} \mathrm{~kg}^{-1}$ in the tropical oceans, especially for $Q_{a}>16 \mathrm{~g} \mathrm{~kg}^{-1}$ (Fig. 1c). However, the LHF has a rather small negative bias of $\sim-2.6 \mathrm{~W} \mathrm{~m}^{-2}$ in the tropical oceans. This is mainly due to the fact that, in the tropical oceans, the GSSTF2 flux model produces a small positive bias of $\sim 5 \mathrm{~W} \mathrm{~m}^{-2}$ for LHF (Chou et al. 2003) and that the weak winds associated with moist air have a small positive bias of $\sim 0.3 \mathrm{~m} \mathrm{~s}^{-1}$ (Table 2). These two factors offset the underestimation of LHF due to a positive bias of humidity.

Sources of retrieval-ship differences in daily LHF and input parameters include the spatialtemporal mismatch between GSSTF2 and ships, as well as the errors in the input parameters and fluxes for both GSSTF2 and ship observations. The collocated daily GSSTF2 variables are 
computed from 2-3 satellite observations averaged over a $1^{\circ}$ area that encloses the ship locations, while those of the ships are computed from at least two hourly measurements over a much smaller area. Assuming daily retrieval errors are independent, Table 2 shows the SD errors for the monthly-mean LHF reduce to 6.5 and $5.4 \mathrm{~W} \mathrm{~m}^{-2}$, as inferred from the nine and five tropical experiments, respectively. The SD errors for the monthly-mean $U, Q_{a}$, and SST reduce to 0.25 $(0.20) \mathrm{m} \mathrm{s}^{-1}, 0.22(0.20) \mathrm{g} \mathrm{kg}^{-1}$, and $0.09^{\circ} \mathrm{C}\left(0.05^{\circ} \mathrm{C}\right)$, respectively, as inferred from the nine (five tropical) experiments.

\section{Comparison of relevant input parameters}

a. Surface wind speeds

The $U_{10 \mathrm{~m}}$ averaged over 1992-93 for GSSTF2, and the differences $U_{10 \mathrm{~m}}$ (HOAPS - GSSTF2), $\mathrm{U}_{10 \mathrm{~m}}\left(\mathrm{NCEP}\right.$ - GSSTF2), and $\mathrm{U}_{10 \mathrm{~m}}$ (da Silva - GSSTF2), respectively, for the 2-yr period over global oceans are shown in Fig. 2. Figure 2a shows that the maximum annual mean wind speed is located in the trade-wind belts $\left(\sim 8-9 \mathrm{~m} \mathrm{~s}^{-1}\right)$ and extratropical storm-track regions $\left(\sim 8-11 \mathrm{~m} \mathrm{~s}^{-1}\right)$. The minimum wind speed is located in the weak-wind $\left(\sim 4-6 \mathrm{~m} \mathrm{~s}^{-1}\right)$ areas of equatorial Indian Ocean, South Pacific convergence zone (SPCZ), and intertropical convergence zone (ITCZ), and the subtropical highs $\left(\sim 7 \mathrm{~m} \mathrm{~s}^{-1}\right)$. Figure $2 \mathrm{~b}$ shows that the HOAPS $\mathrm{U}_{10 \mathrm{~m}}$ is significantly smaller than GSSTF2 in the tropical oceans with a difference up to $2 \mathrm{~m} \mathrm{~s}^{-1}$ centered around the locations of the maximum wind in the trade wind belts of both hemispheres. Over the extratropical oceans, on the contrary, the HOAPS $U_{10 \mathrm{~m}}$ is larger than GSSTF2 with a maximum difference of 2 and $1.5 \mathrm{~m} \mathrm{~s}^{-1}$, centered near $50^{\circ} \mathrm{N}$ and $50^{\circ} \mathrm{S}$, respectively.

Figure 2c shows that the NCEP $U_{10 m}$ is also significantly smaller than GSSTF2 in the tropics (equatorward of $\sim 40^{\circ}$, except the eastern boundary current regions in the Pacific and Atlantic), with the maximum difference of $2 \mathrm{~m} \mathrm{~s}^{-1}$ near the equator. Over the extratropics, the NCEP $\mathrm{U}_{10 \mathrm{~m}}$ is larger than GSSTF2 with the maximum difference of 0.5 and $1 \mathrm{~m} \mathrm{~s}^{-1}$ around $50^{\circ} \mathrm{N}$ and $50^{\circ} \mathrm{S}$, respectively. Figure $2 d$ shows that $U_{10 m}$ (da Silva - GSSTF2) has small-scale features and is quite different with the large-scale patterns of $U_{10 m}\left(H O A P S\right.$ - GSSTF2) and $U_{10 m}(N C E P$ - GSSTF2) shown in Figs. $2 \mathrm{~b}$ and $2 \mathrm{c}$. Over the oceans north of $\sim 10^{\circ} \mathrm{N}, \mathrm{U}_{10 \mathrm{~m}}$ (da Silva - GSSTF2) is generally positive in the high wind areas of extratropical storm track regions and trade wind belts (by $\sim 2-3 \mathrm{~m} \mathrm{~s}^{-1}$ ), but is 
generally negative in the weak wind areas of subtropical highs (by $\sim 1-2 \mathrm{~m} \mathrm{~s}^{-1}$ ). Over the oceans south of $10^{\circ} \mathrm{N}$, it characterizes the small-scale features with neighboring significant large positive and negative difference centers, especially with the magnitude of $U_{10 \mathrm{~m}}$ difference reaching $\sim 4-5 \mathrm{~m} \mathrm{~s}$ ${ }^{1}$ over the data void region of the eastern South Pacific.

Figure 3 shows the standard deviations of differences (SDD) and temporal cross correlation of monthly $\mathrm{U}_{10 \mathrm{~m}}$ between GSSTF2 and each of HOAPS, NCEP, and da Silva, respectively, during 1992-93. The SDD fields are shown in the left column, while those of correlation are shown in the right column. Small SDD indicates a small temporal variability for the monthly differences between datasets, or small dispersions from the mean difference fields shown in Fig. 2. Figures 3a and $3 \mathrm{~b}$ show that, over most of the tropical oceans, the SDD in $U_{10 \mathrm{~m}}$ generally has a small value of $\sim 0.5-0.7 \mathrm{~m} \mathrm{~s}^{-1}$ with high correlation of $>0.9$, which implies that monthly $\mathrm{U}_{10 \mathrm{~m}}$ (HOAPS - GSSTF2) has a small temporal variability there. This indicates that the $U_{10 \mathrm{~m}}$ of HOAPS and GSSTF2 have a large systematical difference (Fig. 2b) but with similar temporal variability in the tropical oceans. In the extratropical oceans, the SDD in $U_{10 \mathrm{~m}}$ is generally $\sim 0.5-1.0 \mathrm{~m} \mathrm{~s}^{-1}$ with high correlation of $\sim 0.8-0.9(\sim 0.8)$ in the north (south), which implies that monthly $U_{10 m}$ (HOAPS - GSSTF2) has a slightly increased temporal variability there.

Figures $3 c$ and $3 d$ show that, poleward of $\sim 10^{\circ}$, the $S D D$ in $U_{10 m}$ generally has a small value of $\sim 0.5-0.7 \mathrm{~m} \mathrm{~s}^{-1}$ with high correlation of $>0.9(0.8-0.9)$ in the north (south), which implies that monthly $U_{10 m}($ NCEP - GSSTF2) has a small temporal variability there during 1992-93. Within $\sim 10^{\circ}$ of equator, the SDD in $\mathrm{U}_{10 \mathrm{~m}}$ is generally $\sim 0.7-1.0 \mathrm{~m} \mathrm{~s}^{-1}$ with the correlation reduced to $\sim 0.3-0.6$, which implies that monthly $U_{10 \mathrm{~m}}(\mathrm{NCEP}-\mathrm{GSSTF} 2)$ has a large temporal variability there. Figures $3 \mathrm{e}$ and $3 \mathrm{f}$ show that the SDD in $U_{10 \mathrm{~m}}$ generally has a large value of $\sim 1-1.5 \mathrm{~m} \mathrm{~s}^{-1}$ over most of the global oceans with poor correlation of $<0.6$ in the oceans south of $30^{\circ} \mathrm{N}(\sim 0.8-0.9$ in the ocean north of $30^{\circ} \mathrm{N}$ ). This indicates that the monthly $\mathrm{U}_{10 \mathrm{~m}}$ of da Silva and GSSTF2 do not correlate well and that monthly $U_{10 \mathrm{~m}}$ (da Silva - GSSTF2) has a large temporal variability over most of the global oceans, especially over the large data-void areas of the Southern Hemisphere.

The Wentz (1997) SSM/I $U_{10 \mathrm{~m}}$ from 1987 to 1997 have been extensively evaluated with those of the Tropical Atmosphere-Ocean (TAO) and National Data Buoy Center (NDBC) buoys by 
Mears et al. (2001), and those of the ECMWF analysis and NCEP by Meissner et al. (2001). Meissner et al. (2001) pointed out that both global analyses did not assimilate the Wentz wind products and that the SSM/I wind speeds assimilated in NCEP were derived using a neural network algorithm and were different from those of Wentz (1997). Mears et al. (2001) found that the mean difference between SSM/I and buoy winds was typically $<0.4 \mathrm{~m} \mathrm{~s}^{-1}$ and the SD error was $<1.4 \mathrm{~m} \mathrm{~s}^{-}$ 1. Meissner et al. (2001) found that the collocated SSM/I and NCEP $\mathrm{U}_{10 \mathrm{~m}}$ had a SD difference of $2.4 \mathrm{~m} \mathrm{~s}^{-1}$, which reduced to $1.2 \mathrm{~m} \mathrm{~s}^{-1}$ for the monthly averages, and that the NCEP $U_{10 \mathrm{~m}}$ was underestimated in the tropical Pacific and tropical Atlantic. Wang and McPhaden (2001) found the NCEP surface winds were weaker than those of TAO buoys by $\sim 1-1.5 \mathrm{~m} \mathrm{~s}^{-1}$ in the tropical Pacific. Smith et al. (2001) found the NCEP $U_{10 m}$ was underestimated by $0.4-1.0 \mathrm{~m} \mathrm{~s}^{-1}$ for five geographic regions (the North Atlantic, South Atlantic, Southern Ocean, Western Pacific, and Arabian Sea), as compared to those measured by research ships during the 1990-95 World Ocean Circulation Experiment. Renfrew et al. (2002) found that the NCEP $\mathrm{U}_{10 \mathrm{~m}}$ was $0.4 \mathrm{~m} \mathrm{~s}^{-1}$ higher than those measured by the research ship over the Labrador Sea. These results are consistent with this study (Table 2 and Fig. 2c).

Da Silva et al. (1994) assumed an anemometer height of $20 \mathrm{~m}$ to the entire wind dataset measured by ship anemometers of COADS to derive a Beaufort equivalent scale for determining visual wind speeds, which depend on sea states. However, Kent and Taylor (1997) found that the true anemometer heights had large standard deviations with the means generally much higher than $20 \mathrm{~m}$ and increasing with time. For example, they found that the mean anemometer height was 35.2 $\mathrm{m}(24.2 \mathrm{~m})$ with a standard deviation of $8.4 \mathrm{~m}(10.9 \mathrm{~m})$ in middle latitudes of the North Pacific (North Atlantic) during 1990. An underestimation of anemometer height can cause unrealistic higher ship anemometer-measured (and visual) wind speeds, because the higher wind speeds measured at the higher anemometer heights are assigned to the assumed lower levels. For the same error of anemometer height, the stronger the wind is, the larger the wind speed error is. This can cause a larger discrepancy of wind speeds in the high-wind regions. This is likely to be the major reason that a large discrepancy of $U_{10 m}$ in the high-wind region of the Northern Hemisphere is found between da Silva and GSSTF2. 
Table 2 and Fig. $1 \mathrm{~b}$ suggested that the GSSTF2 monthly wind speed has a bias of $0.36(0.31)$ $\mathrm{m} \mathrm{s}^{-1}$, and a SD error of $0.25(0.20) \mathrm{m} \mathrm{s}^{-1}$, respectively, as inferred from the nine (five tropical) experiments. This result and the above mentioned previous studies suggest that the GSSTF2 $U_{10 \mathrm{~m}}$ is more accurate and that the differences and SDD of $U_{10 \mathrm{~m}}$ shown in Figs. 2 and 3 are most likely mainly caused by the errors in HOAPS, NCEP, and da Silva.

b. Surface air specific humidity

Figure 4 shows the $Q_{10 m}$ averaged over 1992-93 for GSSTF2, and the differences $\mathrm{Q}_{10 \mathrm{~m}}\left(\right.$ HOAPS - GSSTF2), $\mathrm{Q}_{10 \mathrm{~m}}\left(\mathrm{NCEP}\right.$ - GSSTF2), and $\mathrm{Q}_{10 \mathrm{~m}}$ (da Silva - GSSTF2), respectively, over global oceans. Figure $4 \mathrm{a}$ shows that the $\mathrm{Q}_{10 \mathrm{~m}}$ has a maximum of $>18 \mathrm{~g} \mathrm{~kg}^{-1}$ in the equatorial warm pool and decreases poleward, with the pattern similar to that of SST. The large-scale patterns of $\mathrm{Q}_{10 \mathrm{~m}}$ for HOAPS, NCEP, and da Silva averaged over 1992-93 (not shown) are similar to that of GSSTF2. However, Figs. $4 \mathrm{~b}-4 \mathrm{~d}$ show significant differences with GSSTF2. Figure $4 \mathrm{~b}$ shows that the HOAPS $\mathrm{Q}_{10 \mathrm{~m}}$ is higher than GSSTF2 over the global oceans with the maximum difference of $1.0-1.5 \mathrm{~g} \mathrm{~kg}^{-1}$ in the tropics with high SST. The minimum $\mathrm{Q}_{10 \mathrm{~m}}$ difference of $<\sim 0.5 \mathrm{~g} \mathrm{~kg}^{-1}$ is located in the areas poleward of $\sim 50^{\circ}$, as well as the dry tongue regions of the eastern South Pacific and Atlantic.

Figure $4 c$ shows that, over the equatorial Indian Ocean, SPCZ, and ITCZ, the NCEP $Q_{10 m}$ is smaller than GSSTF 2 by $\sim 0.5-1.0 \mathrm{~g} \mathrm{~kg}^{-1}$, while it is significantly larger than GSSTF2 by $\sim 0.5-2.5$ $\mathrm{g} \mathrm{kg}^{-1}$ for the rest of the global oceans. The maximum difference in $\mathrm{Q}_{10 \mathrm{~m}}$ is $\sim 2.5 \mathrm{~g} \mathrm{~kg}^{-1}$ in the trade wind and dry tongue area of the eastern South Pacific, $\sim 2 \mathrm{~g} \mathrm{~kg}^{-1}$ in the other trade wind areas and $\sim 1 \mathrm{~g} \mathrm{~kg}^{-1}$ in the extratropical oceans. We note that the dry tongue of the HOAPS $\mathrm{Q}_{10 \mathrm{~m}}$ is similar to that of GSSTF2 over the eastern South Pacific, but the dry tongue of NCEP is significantly weaker than that of GSSTF2 (not shown). This result can be inferred from Figs. $4 \mathrm{~b}$ and $4 \mathrm{c}$. Figure $4 \mathrm{~d}$ shows that $\mathrm{Q}_{10 \mathrm{~m}}$ (da Silva - GSSTF2) is characterized by small-scale features with large magnitudes of differences over data sparse regions, especially the equatorial Pacific and oceans south of $\sim 30^{\circ} \mathrm{S}$. The large-scale pattern of $\mathrm{Q}_{10 \mathrm{~m}}\left(\mathrm{da}\right.$ Silva - GSSTF2) (Fig. 4d) is similar to that of $\mathrm{Q}_{10 \mathrm{~m}}(\mathrm{NCEP}$ GSSTF2) (Fig. 4c) north of $\sim 25^{\circ} \mathrm{S}$ but is quite different south of $25^{\circ} \mathrm{S}$. This is because the same observed surface air humidity data of COADS were used in both NCEP and da Silva. 
We note that the $\mathrm{Q}_{10 \mathrm{~m}}$ of da Silva undulates in the zonal direction (which is very different from the large-scale and smoothing patterns of other three data sets) and does not follow the SST pattern south of $\sim 30^{\circ} \mathrm{S}$ (not shown). Thus there are significant smaller scale differences in the zonal belt of $30^{\circ} \mathrm{S}-50^{\circ} \mathrm{S}$ (Fig. 4d). In addition, the $\mathrm{Q}_{10 \mathrm{~m}}$ of da Silva is generally lower than GSSTF2 in the equatorial areas (where the $\mathrm{Q}_{10 \mathrm{~m}}$ is the highest) but is generally higher than GSSTF2 poleward of these regions. Compared to GSSTF2, the da Silva $Q_{10 \mathrm{~m}}$ thus has smaller poleward gradient, which is an indication of a smoothing effect from the successive corrections of da Silva. The positive differences are especially large south of $30^{\circ} \mathrm{S}$. Since data are scarce in the oceans south of $30^{\circ} \mathrm{S}$, the high $\mathrm{Q}_{10 \mathrm{~m}}$ (and SST) observed further equatorward is extrapolated poleward (Kent et al. 2000). This can cause da Silva to have unrealistic high values of $\mathrm{Q}_{10 \mathrm{~m}}$ (and SST) south of $30^{\circ} \mathrm{S}$ and to have large differences with GSSTF2 there (Figs. 4d and 5d).

Since there is no "ground truth" of surface air humidity over global oceans, we analyze the humidity discrepancies based on Table 2, Fig. 1c, and previous studies. Table 2 shows that the GSSTF2 $\mathrm{Q}_{\mathrm{a}}$ has a positive bias of $\sim 1(\sim 0.7) \mathrm{g} \mathrm{kg}^{-1}$ in the tropical oceans (for the nine experiments over the tropical and midlatitude oceans). Figure 1c shows that the GSSTF2 $Q_{a}$ has a positive bias for the moist region with $\mathrm{Q}_{\mathrm{a}}$ of $\sim 16-20 \mathrm{~g} \mathrm{~kg}^{-1}$ but has a small negative bias for the dry region with $\mathrm{Q}_{\mathrm{a}}$ of $\sim 3-6 \mathrm{~g} \mathrm{~kg}^{-1}$. Thus Table 2, and Figs. 1c, 4a, and Fig. $4 \mathrm{~b}$ suggest that the HOAPS $\mathrm{Q}_{10 \mathrm{~m}}$ is significantly overestimated in the tropical oceans, as it is larger than the moist biased $Q_{a}$ of GSSTF2. In addition, Wang and McPhaden (2001), Smith et al. (2001), and Renfrew et al. (2002) found that the NCEP surface air humidity had positive biases when compared with those measured by TAO buoys and research ships. Their results and this study imply that the positive $\mathrm{Q}_{10 \mathrm{~m}}$ (NCEP - GSSTF2) shown in Fig. $4 \mathrm{c}$ is mostly a result of the moist bias of NCEP, while the negative $\mathrm{Q}_{10 \mathrm{~m}}(\mathrm{NCEP}-\mathrm{GSSTF} 2)$ is likely mostly due to the moist bias of GSSTF2.

Previous studies (e.g., da Silva et al. 1994; Chou et al. 1997; Josey et al. 1999) found that ship observations overestimated dew point temperatures (by $\sim 0.5^{\circ} \mathrm{C}$ ), which resulted in moist bias of the surface air humidity for COADS, and thus for da Silva and NCEP. Their results and this study suggest that the moist bias of da Silva is likely responsible for the positive $\mathrm{Q}_{10 \mathrm{~m}}$ (da Silva - 
GSSTF2) shown in Fig. 4d. These analyses suggest that the GSSTF2 $\mathrm{Q}_{10 \mathrm{~m}}$ is likely to have better quality than other three datasets analyzed, although it is still subject to regional biases. More extensive measurements of high quality surface meteorology over the global oceans are essential for further validations.

c. Sea-air humidity differences

Figure 5 shows the $Q_{s}-Q_{10 m}$ averaged over 1992-93 for GSSTF2, and the differences $\left[\left(\mathrm{Q}_{\mathrm{s}}-\mathrm{Q}_{10 \mathrm{~m}}\right)(\mathrm{HOAPS}-\mathrm{GSSTF} 2)\right],\left[\left(\mathrm{Q}_{\mathrm{s}}-\mathrm{Q}_{10 \mathrm{~m}}\right)(\mathrm{NCEP}-\mathrm{GSSTF} 2)\right]$, and $\left[\left(\mathrm{Q}_{\mathrm{s}}-\mathrm{Q}_{10 \mathrm{~m}}\right)(\mathrm{da}\right.$ Silva GSSTF2)], respectively, over global oceans. It is noted that there is a $2 \%$ reduction in $\mathrm{Q}_{s}$ due to salinity effect in GSSTF2, HOAPS, and da Silva, but not in NCEP. In addition, there is a sort of cool skin effect on the GSSTF2 $Q_{S}$ due to the use of approximate humidity equation mentioned in section 3. Figure 5a shows that the $\mathrm{Q}_{\mathrm{s}}-\mathrm{Q}_{10 \mathrm{~m}}$ has the maximum values of $\sim 6 \mathrm{~g} \mathrm{~kg}^{-1}$ over the trade wind belts of both hemispheres and decreases to $<\sim 2 \mathrm{~g} \mathrm{~kg}^{-1}$ poleward of $\sim 50^{\circ}$ resulting from the reduction of SST. Over the equatorial region $\left(10^{\circ} \mathrm{S}-10^{\circ} \mathrm{N}\right)$, the $\mathrm{Q}_{\mathrm{s}}-\mathrm{Q}_{10 \mathrm{~m}}$ has a large value of $\sim 5 \mathrm{~g}$ $\mathrm{kg}^{-1}$ in the high SST regions of the Indian Ocean and western Pacific, and decreases eastward in the eastern Pacific due to upwelling-induced decrease in the SST. Figure 5b shows that the HOAPS $\mathrm{Q}_{\mathrm{s}}-\mathrm{Q}_{10 \mathrm{~m}}$ is smaller than GSSTF2 by $\sim 0.5-1$ and $0-0.5 \mathrm{~g} \mathrm{~kg}^{-1}$, respectively, in the areas equatorward and poleward of $\sim 20^{\circ}$. The difference in $\mathrm{Q}_{\mathrm{s}}-\mathrm{Q}_{10 \mathrm{~m}}$ is smaller over the dry or cold tongue areas of the eastern South Pacific and South Atlantic, with the minimum difference $\sim 30^{\circ} \mathrm{S}$.

Figure $5 \mathrm{c}$ shows that, over the regions of equatorial Indian Ocean, SPCZ, and ITCZ, the NCEP $\mathrm{Q}_{\mathrm{S}}-\mathrm{Q}_{10 \mathrm{~m}}$ is significantly larger than GSSTF 2 by $\sim 0.5-1.5 \mathrm{~g} \mathrm{~kg}^{-1}$. For the rest of the global oceans, it is significantly smaller than GSSTF 2 by $\sim 0.5-2.0 \mathrm{~g} \mathrm{~kg}^{-1}$, with the maximum difference reaching $\sim 2 \mathrm{~g} \mathrm{~kg}^{-1}$ over the trade wind area in the eastern South Pacific, up to $\sim 1.5 \mathrm{~g} \mathrm{~kg}^{-1}$ in the other trade wind areas, and $\sim 1 \mathrm{~g} \mathrm{~kg}^{-1}$ in the extratropical oceans. Figure $5 \mathrm{~d}$ shows that the $\left[\left(\mathrm{Q}_{\mathrm{s}}-\mathrm{Q}_{10 \mathrm{~m}}\right)(\mathrm{da}\right.$ Silva - GSSTF2)] has small-scale structures with large magnitudes of differences over data sparse regions, especially the equatorial Pacific and the oceans south of $30^{\circ} \mathrm{S}$. The large-scale pattern of $\left[\left(Q_{s}-Q_{10 m}\right)\left(\right.\right.$ da Silva - GSSTF2)] (Fig. 5d) is similar to that of $\left[\left(Q_{s}-Q_{10 m}\right)(N C E P-G S S T F 2)\right]$ (Fig. 5c) north of $\sim 25^{\circ} \mathrm{S}$ but is quite different south of $25^{\circ} \mathrm{S}$. It can be seen from Figs. 4 and 5 that, for these datasets, the differences in $Q_{10 m}$ mainly control the differences in $Q_{s}-Q_{10 m}$ and the 
differences in $\mathrm{Q}_{S}$ is relatively small (see Table 3), which is consistent with the results of Chou et al. (2003).

Figure 6 shows the SDD and temporal cross correlation of monthly $\mathrm{Q}_{\mathrm{s}}-\mathrm{Q}_{10 \mathrm{~m}}$ between GSSTF2 and each of HOAPS, NCEP, and da Silva, respectively, during 1992-93. Figures 6a and 6b show that, over most of the oceans, the SDD in $\mathrm{Q}_{\mathrm{S}}-\mathrm{Q}_{10 \mathrm{~m}}$ is $\sim 0.4-0.7 \mathrm{~g} \mathrm{~kg}^{-1}\left(<0.4 \mathrm{~g} \mathrm{~kg}^{-1}\right.$ or smaller near the dry tongues and polar regions) with a moderate high correlation of $\sim 0.7-0.9$ (slightly smaller than the correlation of $\left.U_{10 m}\right)$. This implies that the monthly $\left[\left(Q_{s}-Q_{10 m}\right)(H O A P S-G S S T F 2)\right]$ has a moderate temporal variability over most of the oceans. Over the tropical oceans where the HOAPS $\mathrm{Q}_{\mathrm{S}}-\mathrm{Q}_{10 \mathrm{~m}}$ is significantly smaller than GSSTF2 (Fig. 5b), there is high correlation associated with relatively small SDD in $\mathrm{Q}_{\mathrm{S}}-\mathrm{Q}_{10 \mathrm{~m}}$. This indicates that the monthly $\mathrm{Q}_{\mathrm{s}}-\mathrm{Q}_{10 \mathrm{~m}}$ of HOAPS is systematically smaller than that of GSSTF2, but with the similar temporal variability as that of GSSTF2.

Figures $6 \mathrm{c}$ and $6 \mathrm{~d}$ show that, over the tropical oceans, the $\mathrm{SDD}$ in $\mathrm{Q}_{\mathrm{s}}-\mathrm{Q}_{10 \mathrm{~m}}$ has a large value of $\sim 1-1.5 \mathrm{~g} \mathrm{~kg}^{-1}$ with low correlation of $<0.3$ (reducing to about -0.3 in the equatorial Pacific and Indian oceans). This implies that the monthly $\left[\left(\mathrm{Q}_{\mathrm{S}}-\mathrm{Q}_{10 \mathrm{~m}}\right)(\mathrm{NCEP}-\mathrm{GSSTF} 2)\right]$ has a very large temporal variability over the tropical oceans during 1992-93. In the extratropical oceans, the SDD in $\mathrm{Q}_{\mathrm{S}}-\mathrm{Q}_{10 \mathrm{~m}}$ decreases to $\sim 0.4-0.7 \mathrm{~g} \mathrm{~kg}^{-1}$ and the correlation increases to $\sim 0.6-0.9$. This implies that the monthly $\left[\left(\mathrm{Q}_{\mathrm{S}}-\mathrm{Q}_{10 \mathrm{~m}}\right)(\mathrm{NCEP}-\mathrm{GSSTF} 2)\right]$ has a reduced temporal variability over the extratropical oceans, as compared to over the tropical oceans. Figures $6 e$ and $6 f$ show that the SDD in $\mathrm{Q}_{s}-\mathrm{Q}_{10 \mathrm{~m}}$ has a large value of $\sim 0.7-1.5 \mathrm{~g} \mathrm{~kg}^{-1}$ equatorward of $\sim 40^{\circ} \mathrm{N}\left(\sim 0.5 \mathrm{~g} \mathrm{~kg}^{-1}\right.$ poleward of $\left.\sim 40^{\circ} \mathrm{N}\right)$ with very low correlation of $<0.3$ over most of the oceans south of $\sim 30^{\circ} \mathrm{N}$. This implies that the monthly $\left[\left(\mathrm{Q}_{\mathrm{s}}-\mathrm{Q}_{10 \mathrm{~m}}\right)\right.$ (da Silva - GSSTF2)] has a very large temporal variability over most of the global oceans. Note that the low correlation associated with relatively large SDD in $Q_{S}-Q_{10 m}$ for da Silva, as well as NCEP in the equatorial area, is generally located in the data sparse regions (e.g., da Silva et al. 1994; Chou et al. 1997; Josey et al. 1999). This may be due to the errors of $\mathrm{Q}_{10 \mathrm{~m}}$ arising from the interpolation scheme of da Silva and the shortcoming of the boundary layer and cumulus parameterization used in NCEP, as the correlation of $\mathrm{Q}_{\mathrm{S}}-\mathrm{Q}_{10 \mathrm{~m}}\left(\right.$ or $\mathrm{Q}_{10 \mathrm{~m}}$ ) between GSSTF2 and HOAPS is generally high over these areas. 


\section{Comparison of LHF}

The LHF averaged over 1992-93 for GSSTF2, and the differences LHF(HOAPS - GSSTF2), LHF(NCEP - GSSTF2), and LHF(da Silva - GSSTF2), respectively, for the 2-yr period over global oceans are shown in Fig. 7. Figure 7a shows that the maximum LHF is located in the trade wind belts of both hemispheres $\left(\sim 160-180 \mathrm{~W} \mathrm{~m}^{-2}\right)$ and in the western boundary current regions of the Kuroshio and Gulf Stream $\left(\sim 160 \mathrm{~W} \mathrm{~m}^{-2}\right)$. This results from high winds $\left(\sim 8-9 \mathrm{~m} \mathrm{~s}^{-1}\right)$ coupling with large $\mathrm{Q}_{\mathrm{s}}-\mathrm{Q}_{10 \mathrm{~m}}\left(\sim 5-6 \mathrm{~g} \mathrm{~kg}^{-1}\right)$ in these areas (Figs. 2a and 5a). The minimum LHF (< 60 W m${ }^{2}$ ) is found in the eastern equatorial Pacific and Atlantic, due to upwelling-induced cold SSTs associated with weak winds, and in the high latitudes due to poleward decrease of SST. We note that the general patterns of $U_{10 m}, Q_{s}-Q_{10 m}$, and LHF of GSSTF2 for 1992-93 (Figs. 2a, 5a, and 7a) are similar to those of Chou et al. (2003) for 1988-2000. For the 1992-93 mean condition, the large-scale pattern of the GSSTF2 LHF shown in Fig. 7a is similar to those of HOAPS, NCEP, and da Silva (not shown). However, there are significant differences with GSSTF2 geographically.

The moisture transfer coefficients of HOAPS and da Silva are derived based on Smith (1988) and Large and Pond (1982), respectively. Both coefficients are very close to that of GSSTF2. Thus, the discrepancy in the LHF among GSSTF2, HOAPS, and da Silva is primarily caused by the differences in the input parameters. However, this situation is not true for NCEP. The moisture transfer coefficient of NCEP is significantly larger than that of GSSTF2 (and the other two flux datasets; Zeng et al. 1998), which appears to offset the effects of weaker winds and smaller sea-air humidity difference on the LHF (Figs. $2 c$ and 5 c).

Figure $7 \mathrm{~b}$ shows that the HOAPS LHF is significantly smaller than that of GSSTF2 over the global oceans, especially in the tropics. In the tropical oceans, the difference is $\sim 20-60 \mathrm{~W} \mathrm{~m}^{-2}$, with the maximum differences of $\sim 60$ and $40 \mathrm{~W} \mathrm{~m}^{-2}$ centered $\sim 10^{\circ} \mathrm{N}$ and $10^{\circ} \mathrm{S}$, respectively. The difference decreases poleward and is negligible south of $\sim 30^{\circ} \mathrm{S}$. In the tropical oceans, the negative LHF(HOAPS - GSSTF2) is a result of smaller $U_{10 m}$ and $Q_{S}-Q_{10 m}$ of HOAPS (Figs. $2 b$ and $5 b$ ). For the negative LHF(HOAPS - GSSTF2) in the oceans north of $30^{\circ} \mathrm{N}$, the effect of the smaller HOAPS $Q_{s}-Q_{10 m}$ (coupling with high winds) slightly overcompensates the effect of higher $U_{10 \mathrm{~m}}$ 
(coupling with low $\mathrm{Q}_{\mathrm{S}}-\mathrm{Q}_{10 \mathrm{~m}}$ ) on the LHF. For the negligible LHF difference in the oceans south of $\sim 30^{\circ} \mathrm{S}$, the effects of smaller $\mathrm{Q}_{\mathrm{S}}-\mathrm{Q}_{10 \mathrm{~m}}$ and larger $\mathrm{U}_{10 \mathrm{~m}}$ on LHF generally offset each other.

Figure $7 c$ shows that the NCEP LHF is larger than GSSTF2 in the equatorial Indian Ocean, SPCZ, ITCZ, the Kuroshio and Gulf Stream, and subtropics, with the maximum difference up to 40 $\mathrm{W} \mathrm{m}^{-2}$. For the rest of the global oceans, the NCEP LHF is smaller than GSSTF2, with the maximum difference of $\sim 60 \mathrm{~W} \mathrm{~m}^{-2}$ located in the dry tongue and trade wind region of the eastern South Pacific. For the trade wind regions (especially over the South Pacific dry tongue), the negative LHF(NCEP - GSSTF2) is a result of smaller $U_{10 m}$ and $Q_{s}-Q_{10 m}$ of NCEP (Figs. $2 c$ and 5c). The positive LHF(NCEP - GSSTF2) in the equatorial Indian Ocean, SPCZ, and ITCZ is due to the effects of larger NCEP $Q_{S}-Q_{10 m}$ and moisture transfer coefficient overcompensating the effect of smaller $U_{10 m}$ on the LHF. The negative LHF(NCEP - GSSTF2) in the extratropical oceans is due to the effect of smaller NCEP $Q_{s}-Q_{10 m}$ overcompensating the effects of larger $U_{10 m}$ and moisture transfer coefficient on the LHF.

Figure 7d shows the LHF(da Silva - GSSTF2) has small-scale structures, with its large-scale pattern somewhat similar to that of LHF(NCEP - GSSTF2) (Fig. 7c). For example, the da Silva LHF is larger than GSSTF2 in the equatorial Indian Ocean, SPCZ, ITCZ, and the Kuroshio area, but with a larger difference of $20-60 \mathrm{~W} \mathrm{~m}^{-2}$. In addition, the da Silva LHF is smaller than GSSTF2 in the trade wind regions and the oceans south of $30^{\circ} \mathrm{S}$, but with significantly larger localized differences of $20-80 \mathrm{~W} \mathrm{~m}^{-2}$. Note that Fig. $7 \mathrm{~d}$ shows that there are some neighboring extreme large positive and negative difference centers of LHF located in the data sparse regions for da Silva. This feature is quite different than the more organized large-scale patterns of LHF difference for HOAPS and NCEP (Figs. $7 \mathrm{~b}$ and 7c).

Figure 8 shows the SDD and temporal cross correlation of monthly LHF between GSSTF2 and each of HOAPS, NCEP, and da Silva, respectively, during 1992-93 over global oceans. Figure $8 \mathrm{a}$ and $8 \mathrm{~b}$ show that the SDD in LHF is generally $\sim 10-20 \mathrm{~W} \mathrm{~m}^{-2}$ over the oceans, with a high correlation of $0.8-0.9(0.6-0.8)$ in the oceans north of $\sim 20^{\circ} \mathrm{S}$ (south of $20^{\circ} \mathrm{S}$ ). This implies that the monthly LHF(HOAPS - GSSTF2) has a relatively smaller temporal variability in the oceans north of $20^{\circ} \mathrm{S}$ than the ocean south of $20^{\circ} \mathrm{S}$. 
Figure $8 \mathrm{c}$ and $8 \mathrm{~d}$ show that, over the tropical oceans, the SDD in LHF has a large value of $\sim 20-30 \mathrm{~W} \mathrm{~m}^{-2}$ with a low correlation of $0.6-0.9(0.3-0.6$ in the ITCZ), which implies that the monthly LHF (NCEP - GSSTF2) has a large temporal variability there, especially over the ITCZ. In the extratropical oceans, the SDD in LHF reduces to $\sim 10-20 \mathrm{~W} \mathrm{~m}^{-2}$ with an increased correlation of $0.8-0.9$ (larger for the northern than the southern extratropical oceans). This implies that the monthly LHF (NCEP - GSSTF2) has a smaller temporal variability in the extratropical oceans than in the tropical oceans. Figure 8e and $8 \mathrm{f}$ show that the SDD in LHF generally has a large value of $-20-40 \mathrm{~W} \mathrm{~m}^{-2}$ over most of the global oceans, with the correlation of $<0.6$ over most of the areas south of $\sim 30^{\circ} \mathrm{N}$. This implies that the monthly LHF(da Silva - GSSTF2) has a large temporal variability over most of the oceans, especially the equatorial and southern extratropical oceans

Table 3 shows the regional averages of LHF and input parameters for the global oceans $\left(60^{\circ} \mathrm{S}-60^{\circ} \mathrm{N}\right)$, northern extratropical oceans $\left(20^{\circ} \mathrm{N}-60^{\circ} \mathrm{N}\right)$, tropical oceans $\left(20^{\circ} \mathrm{S}-20^{\circ} \mathrm{N}\right)$, and southern extratropical oceans $\left(20^{\circ} \mathrm{S}-60^{\circ} \mathrm{S}\right)$ during $1992-93$ for GSSTF2, as well as the differences of HOAPS, NCEP, and da Silva from GSSTF2. The global-mean LHF is the largest for GSSTF2 $\left(108.2 \mathrm{~W} \mathrm{~m}^{-2}\right)$ and is the smallest for HOAPS $\left(88.5 \mathrm{~W} \mathrm{~m}^{-2}\right)$, with a difference of $20 \mathrm{~W} \mathrm{~m}^{-2}$. Over the tropical oceans, the HOAPS LHF is significantly smaller than GSSTF2 by $\sim 31 \%\left(37 \mathrm{~W} \mathrm{~m}^{-2}\right)$, whereas the other two datasets are comparable to GSSTF2. This is because the HOAPS LHF is systematically smaller than GSSTF2 in space, while the other two datasets have very large spatial variations in LHF with large positive and negative differences, which cancel to produce smaller regional-mean differences (Fig. 7). The smallness of HOAPS LHF in the tropical oceans is mainly a result of weaker $U_{10 \mathrm{~m}}$ (by $\sim 1.1 \mathrm{~m} \mathrm{~s}^{-1}$ ) coupling with smaller $\mathrm{Q}_{\mathrm{S}}-\mathrm{Q}_{10 \mathrm{~m}}$ (by $\sim 0.7 \mathrm{~g} \mathrm{~kg}^{-1}$ ). The significant larger $Q_{10 m}$ (by $1.1 \mathrm{~g} \mathrm{~kg}^{-1}$ ) is the main cause for the smallness of HOAPS $Q_{s}-Q_{10 m}$.

The global-mean LHF of NCEP is comparable to that of GSSTF2, but $U_{10 \mathrm{~m}}$ and $\mathrm{Q}_{\mathrm{s}}-\mathrm{Q}_{10 \mathrm{~m}}$ are smaller (by $\sim 0.6 \mathrm{~m} \mathrm{~s}^{-1}$ and $\sim 0.5 \mathrm{~g} \mathrm{~kg}^{-1}$ ), which appear to offset the larger moisture transfer coefficient (Zeng et al. 1998). Due to the cancellation of large local positive and negative differences with GSSTF2, the regional-mean LHF of da Silva appears to be comparable to that of GSSTF2, except for the southern extratropical oceans. Over the southern extratropics, the da Silva 
LHF is the smallest among the four datasets (Fig. 7 and Table 3), $23 \%\left(22 \mathrm{~W} \mathrm{~m}^{-2}\right)$ smaller than GSSTF2. This discrepancy is mainly due to the larger $\mathrm{Q}_{10 \mathrm{~m}}\left(\right.$ by $\sim 1.2 \mathrm{~g} \mathrm{~kg}^{-1}$ ) and is most likely due to the errors arising from the interpolation of missing data in the large data-void regions (from the relatively high $\mathrm{Q}_{10 \mathrm{~m}}$ in the low to mid-latitudes) as discussed before (see Fig. 4d).

Table 4 shows regional-mean standard deviation of differences/temporal cross correlation of monthly LHF and input parameters for the global oceans, northern extratropical oceans, tropical oceans, and southern extratropical oceans between GSSTF2 and each of HOAPS, NCEP, and da Silva during 1992-93. Note that, for the same region, a low SDD value is associated with a high correlation, indicating similar behavior of two time series. Averaged over the global oceans, HOAPS has the highest correlation in LHF with GSSTF2 (0.81), due to the highest correlation in $\mathrm{U}_{10 \mathrm{~m}}$ and especially $\mathrm{Q}_{\mathrm{S}}-\mathrm{Q}_{10 \mathrm{~m}}$. On the other hand, da Silva has the lowest correlation in LHF with GSSTF2 (0.51), due to the lowest correlation in $U_{10 m}$ and especially $Q_{s}-Q_{10 m}$. The correlation is higher in the northern extratropical oceans than in the south for all variables, with the contrasts especially large for da Silva as a result of more missing data in the south. Over the tropical oceans, NCEP has a very low correlation in LHF with GSSTF2 (0.69). This is primarily a result of very low correlation in $Q_{s}-Q_{10 m}(0.27)$, which is close to that of da Silva (0.31) but is significantly smaller than that of HOAPS $(0.81)$. This may be due to missing data and the shortcoming of the cumulus and boundary parameterization used in NCEP. In short, our analyses suggest that the GSSTF2 LHF, surface air humidity, and winds are likely to be more realistic than the other three datasets analyzed, although those of GSSTF2 are still subject to regional biases. More high-quality observations over global oceans are needed to do a more detailed regional validation and to confirm our conclusion.

\section{Concluding remarks}

The monthly LHF and input parameters $\left(\mathrm{U}_{10 \mathrm{~m}}, \mathrm{Q}_{10 \mathrm{~m}}\right.$, and $\left.\mathrm{Q}_{\mathrm{S}}-\mathrm{Q}_{10 \mathrm{~m}}\right)$ of GSSTF2 over global oceans during 1992-93 are compared with those of HOAPS, NCEP, and da Silva. The large-scale patterns of the 2yr-mean fields for these variables are similar among these four datasets, but significant quantitative differences are found. Over the tropics, the HOAPS LHF is significantly smaller than GSSTF2 by $\sim 31 \%\left(37 \mathrm{~W} \mathrm{~m}^{-2}\right.$ ), whereas the other two datasets are comparable to 
GSSTF2. This is because that HOAPS has systematically smaller LHF than GSSTF2 in space, while the other two datasets have very large spatial variations of large positive and negative LHF differences with GSSTF2 which cancel to produce smaller regional-mean differences. The smallness of the HOAPS LHF is a result of smaller $Q_{s}-Q_{10 m}$ and $U_{10 m}$, with the former mainly due to a larger $\mathrm{Q}_{10 \mathrm{~m}}$ (by $1.1 \mathrm{~g} \mathrm{~kg}^{-1}$ ). Over the northern (southern) extratropical oceans, the HOAPS LHF is smaller than GSSTF 2 by $14 \mathrm{~W} \mathrm{~m}^{-2}\left(2 \mathrm{~W} \mathrm{~m}^{-2}\right)$. Averaged over the global oceans $\left(60^{\circ} \mathrm{S}-60^{\circ} \mathrm{N}\right)$, the HOAPS LHF is smaller than GSSTF 2 by $20 \mathrm{~W} \mathrm{~m}^{-2}$.

In the equatorial Indian Ocean, SPCZ, ITCZ, the Kuroshio and Gulf Stream, and subtropics, the NCEP LHF is larger than GSSTF2, with the maximum difference up to $40 \mathrm{~W} \mathrm{~m}^{-2}$. For the rest of the oceans, it is smaller than GSSTF2, with the maximum difference of $\sim 60 \mathrm{~W} \mathrm{~m}^{-2}$ located in the dry tongue and trade wind region of the eastern South Pacific. The smaller NCEP LHF in the trade wind regions is a result of smaller $\mathrm{Q}_{\mathrm{S}}-\mathrm{Q}_{10 \mathrm{~m}}$ and $\mathrm{U}_{10 \mathrm{~m}}$. For the equatorial Indian Ocean, SPCZ, and ITCZ, the larger NCEP LHF is because the effects of larger NCEP $Q_{s}-Q_{10 m}$ and moisture transfer coefficient overcompensate the effect of smaller $U_{10 m}$ on the LHF. The smaller NCEP LHF in the extratropical oceans is because the effect of smaller NCEP $Q_{S}-Q_{10 \mathrm{~m}}$ overcompensates the effects of larger $U_{10 \mathrm{~m}}$ and moisture transfer coefficient on the LHF. Averaged over the global oceans, the NCEP LHF is smaller than GSSTF2 by only $\sim 3 \mathrm{~W} \mathrm{~m}^{-2}$ due to the large cancellation of local positive and negative differences with GSSTF2. The NCEP has extremely low temporal correlation (0.27) and large spatial variations of differences with GSSTF2 for $\mathrm{Q}_{\mathrm{s}}-\mathrm{Q}_{10 \mathrm{~m}}$ in the tropics, which causes the low correlation for LHF. The very low temporal correlation of $\mathrm{Q}_{\mathrm{S}}-\mathrm{Q}_{10 \mathrm{~m}}$ for NCEP, which is generally located in the data sparse tropics, is close to that of da Silva (0.31) but is significantly smaller than that of HOAPS (0.81).

The LHF difference of da Silva with GSSTF2 has small-scale structures, with its large-scale pattern somewhat similar to that of NCEP, but with larger magnitudes of difference. The da Silva is also found to have some nearby extreme large positive and negative LHF difference centers located in the data sparse regions. This feature is quite different than the more organized large-scale LHF difference patterns of HOAPS and NCEP (with GSSTF2). Due to the cancellation of these large local positive and negative differences, the regional-mean LHF of da Silva appears to be comparable 
to that of GSSTF2, except for the southern extratropical oceans with $\sim 23 \%\left(22 \mathrm{~W} \mathrm{~m}^{-2}\right)$ smaller value than GSSTF2. This discrepancy is mainly due to a larger $\mathrm{Q}_{10 \mathrm{~m}}$ (by $\sim 1.2 \mathrm{~g} \mathrm{~kg}^{-1}$ ) and is most likely due to the errors arising from the interpolation in the large data-void regions. In addition, da Silva has extremely low temporal correlation and large differences with GSSTF2 for all variables in the southern extratropics, indicating that da Silva hardly produces a realistic variability in these variables. The temporal correlation is higher in the northern extratropics than in the south for all variables, with the contrast being especially large for da Silva as a result of more missing ship data in the south.

Our analyses suggest that the GSSTF2 LHF, surface air humidity, and winds are likely to be more realistic than the other three flux products examined, although those of GSSTF2 are still subject to regional biases. This conclusion is consistent with that of Chou et al. (2003). More high-quality observations covering wider areas of the global oceans (or more areas covering different climatic regimes) are vital to do a more complete regional validation, to improve satellite retrieval, and to further confirm our conclusion. The GSSTF2 LHF is useful for climate studies and is available at http://daac.gsfc.nasa.gov/CAMPAIGN_DOCS/hydrology/hd_gsstf2.0.html.

Acknowledgments This study was supported by the TRMM Program and Physical Oceanography Program, NASA/Office of Earth Science. Hourly latent heat fluxes measured by research ships were provided by C. Fairall of the NOAA/ETL through the SEAFLUX website http://paos.colorado.edu/ curryja/ocean/. The NCEP/NCAR reanalysis data were obtained from the NOAA/CIRES Climate Diagnostics Center http://www.cdc.noaa.gov/. The HOAPS latent heat fluxes were obtained from http://www.mpimet.mpg.de/Depts/Physik/HOAPS/. The da Silva latent heat fluxes were provided by A. da Silva. The GSSTF2 latent heat fluxes were obtained from http://daac.gsfc.nasa.gov/CAMPAIGN DOCS/hydrology/hd gsstf2.0.html. 


\section{REFERENCES}

Brunke, M.A., C.W. Fairall, X. Zeng, L. Eymard, and J. A. Curry, 2003: Which bulk aerodynamic algorithms are least problematic in computing ocean surface turbulent fluxes? J. Climate, $16,619-635$.

Chou, S.-H., R. M. Atlas, C.-L. Shie and J. Ardizzone, 1995: Estimates of surface humidity and latent heat fluxes over oceans from SSM/1 data. Mon. Wea. Rev., 123, 2405-2425.

Chou, S.-H., C.-L. Shie, R. M. Atlas and J. Ardizzone, 1997: Air-sea fluxes retrieved from Special Sensor Microwave Imager data. J. Geophys. Res., 102, 12705-12726.

Chou, S.-H., W. Zhao, and M.-D. Chou, 2000: Surface heat budgets and sea surface temperature in the Pacific warm pool during TOGA COARE. J. Climate, 13, 634-649.

Chou, S.-H., E. Nelkin, J. Ardizzone, R. M. Atlas, and C.-L. Shie, 2003: Surface turbulent heat and momentum fluxes over global oceans based on the Goddard satellite retrievals, version 2 (GSSTF2). J. Climate, 16, 3256-3273.

Chou, S.-H., M.-D. Chou, P.-K. Chan, P.-H. Lin, and K.-H Wang, 2003b: Tropical warm pool surface heat budgets and temperature: Contrasts between 1997-98 El Nino and 1998-99 La Nina. J. Climate, (conditionally accepted).

Curry, J. A., and co-authors, 2003: SEAFLUX. Bull. Amer. Meteor. Soc., (in press).

da Silva, A, C. C. Young and S. Levitus, 1994: Atlas of Surface Marine Data 1994 Vol. 1: Algorithms and Procedures. NOAA Atlas NESDIS 6, US Dept. of Commerce, NOAA, NESDIS, Washington, DC, 83 pp.

Fairall, C., E. F. Bradley, D. P. Rogers, J. B. Edson, and G. S. Young, 1996a: Bulk parameterization of air-sea fluxes for Tropical Ocean Global Atmosphere Coupled Ocean-Atmosphere Response Experiment. J. Geophys. Res., 101 (C2), 3747-3764.

Fairall, C. W., E. F. Bradley, J. S. Godfrey, J. B. Edson, G. S. Young, and G. A. Wick, 1996b: Cool-skin and warm-layer effects on sea surface temperature, J. Geophys. Res., 101, 12951308. 
Fairall, C. W., A. B. White, J. B. Edson, and J. E. Hare, 1997: Integrated shipboard measurements of the marine boundary layer. J. Atmos. Oceanic Technol., 14, 338-359.

Fairall, C. W., E. F. Bradley, J. E. Hare, A. A. Grachev, and J. B. Edson, 2003: Bulk parameterization of air-sea fluxes: updates and verification for the COARE algorithm. $J$. Climate, 16, 571-591.

Graßl, H., V. Jost, R. Kumar, J. Schulz, P. Bauer, and P. Schlussel, 2000: The Hamburg OceanAtmosphere Parameters and Fluxes from Satellite Data (HOAPS): A Climatological Atlas of Satellite-Derived Air-Sea-Interaction Parameters over the Oceans. Rep. 312, Max-Planck Institute for Meteorology, Hamburg, Germany, 130pp.

Josey, S. A., E. C. Kent and P. K. Taylor 1999: New insights into the ocean heat budget closure problem from analysis of the SOC air-sea flux climatology. J. Climate, 12, 2856 - 2880.

Kalnay, E., and co-authors, 1996: The NCEP/NCAR 40-year reanalysis project. Bull. Amer. Meteor. Soc., 77, 437-471.

Kent, E. C., and P. K. Taylor, 1997: Choice of a Beaufort equivalent scale. J. Atmos. Oceanic Technol., 14, 228-242.

Kent, E. C., P. K. Taylor and P. G. Challenor, 2000: The characteristics of a sea surface temperature dataset smoothed by successive correction. J. Climatel, 13, 1845-1857.

Kubota, M., K. Ichikawa, N. Iwasaka, S. Kizu, M. Konda, and K. Kutsuwada, 2002: Japanese Ocean Flux Data Sets with Use of Remote Sensing Observations (J-OFURO) introducing J-OFURO. J. Oceanogr., 58, 213-215.

Kubota, M., A. Kano, H. Muramatsu and H. Tomita, 2003: Intercomparison of various surface latent heat flux fields. J. Climate, 16, 670-678.

Large, W. G., and S. Pond, 1982: Sensible and latent heat flux measurements over the ocean. $J$. Phys. Oceanogr., 12, 464-482.

Mears, C. A., D. Smith, and F.J. Wentz, 2001: Comparison of Special Sensor Microwave Imager and buoy-measured wind speeds from 1987 to 1997. J. Geophys. Res., 106, 11719-11729. 
Meissner, T., D. Smith, and F. J. Wentz, 2001: A 10-year intercomparison between collocated SSM/I oceanic surface wind speed retrievals and global analyses. J. Geophys. Res., 106, 11731-11742.

Renfrew, I.A., G.W.K. Moore, P.S. Guest, and K. Bumke, 2002: A comparison of surface layer and surface turbulent flux observations over the Labrador Sea with ECMWF analyses and NCEP reanalyses. J. Phys. Oceanogr., 32, 383-400.

Schulz, J., J. Meywerk, S. Ewald, and P. Schluessel, 1997: Evaluation of satellite-derived latent heat fluxes. J. Climate, 10, 2782-2795.

Smith, S. D., 1988; Coefficients for sea surface wind stress, heat flux, and wind profiles as a function of wind speed and temperature. J. Geophys. Res., 93, 2859-2874.

Smith, S. R., D. M. Legler, and K. V. Verzone, 2001: Quantifying uncertainties in NCEP reanalyses using high-quality research vessel observations. J. Climate. 14, 4062-4072.

Taylor, P. K., and M. A. Yelland, 2001: The dependence of sea surface roughness on the height and steepness of the waves. J. Phys. Oceanogr., 31, 572-590.

Wang, W., and M. J. McPhaden, 2001: What is the mean seasonal cycle of surface heat flux in the equatorial Pacific? J. Geophys. Res., 106, 837-857.

Webster, P., C. A. Clayson, and J. A. Curry, 1996: Clouds, radiation, and the diurnal cycle of sea surface temperature in the tropical western Pacific. J. Climate, 9, 1712-1730.

Wentz, F. J., 1997: A well calibrated ocean algorithm for SSM/I. J. Geophys. Res., 102, 8703-8718.

Wick, G. A., W. J. Emery and L. H. Kantha, 1996: The behavior of the bulk-skin sea surface temperature difference under varying wind speed and heat flux. J. Phys. Oceanogr. 26, 1969-1988.

Woodruff, S. D., S. J. Lubker, K. Wolter, S. J. Worley, and J. D. Elm, 1993: Comprehensive Ocean-Atmosphere Data Set (COADS) release 1a: 1980-92. Earth Syst. Monit., 4, 4-8.

Yelland, M., and P. K. Taylor, 1996: Wind stress measurements from the open ocean. J. Phys. Oceanogr., 26, 541-558. 
Yelland, M., B. I. Moat, P. K. Taylor, R. W. Pascal, J. Hutching, and V. C. Cornell, 1998: Wind stress measurements from the open ocean corrected for airflow distortion by the ship. $J$. Phys. Oceanogr., 28, 1511-1526.

Zeng, X., M. Zhao, and R. E. Dickinson, 1998: Intercomparison of bulk aerodynamic algorithms for the computation of sea surface fluxes using TOGA COARE and TAO data. J Climate, 11, 2628-2644. 
Table 1. Times and locations of nine field experiments conducted by the NOAA/ETL research ships.

\begin{tabular}{lll}
\hline Experiments & Times & Locations \\
\hline ASTEX & $92 / 6 / 6-92 / 6 / 28$ & $30^{\circ} \mathrm{N}, 36^{\circ} \mathrm{W}$ \\
COARE & $92 / 11 / 11-93 / 2 / 16$ & $1.7^{\circ} \mathrm{S}, 156^{\circ} \mathrm{E}$ \\
FASTEX & $96 / 12 / 22-97 / 1 / 26$ & $42-52^{\circ} \mathrm{N}, 5-60^{\circ} \mathrm{W}$ \\
JASMINE & $99 / 5 / 4-99 / 5 / 31$ & $5^{\circ} \mathrm{S}-13^{\circ} \mathrm{N}, 88-98^{\circ} \mathrm{E}$ \\
KWAJEX & $99 / 7 / 28-99 / 9 / 10$ & $9^{\circ} \mathrm{N}, 167^{\circ} \mathrm{E}$ \\
MOORINGS & $99 / 9 / 14-99 / 10 / 21$ & $8^{\circ} \mathrm{N}, 167^{\circ} \mathrm{E}-49^{\circ} \mathrm{N}, 130^{\circ} \mathrm{W}$ \\
NAURU99 & $99 / 6 / 15-99 / 7 / 18$ & $12^{\circ} \mathrm{S}, 130^{\circ} \mathrm{E}-8^{\circ} \mathrm{N}, 167^{\circ} \mathrm{E}$ \\
PACSF 99 & $99 / 11 / 2-99 / 12 / 1$ & $8^{\circ} \mathrm{S}-12^{\circ} \mathrm{N}, 95-121^{\circ} \mathrm{W}$ \\
TIWE & $91 / 11 / 21-91 / 12 / 13$ & $0^{\circ} \mathrm{N}, 140^{\circ} \mathrm{W}$ \\
\hline
\end{tabular}


Table 2. Comparison of daily LHF, surface wind speed (U), surface air specific humidity $\left(Q_{a}\right)$, and SST of GSSTF2 with those of all nine field experiments and five tropical experiments with large samples. The mean is ship-observed values averaged over collocated days, positive bias indicates larger GSSTF2, SD error is std dev of differences, and $r$ is correlation coefficient. Units are W $\mathrm{m}^{-2}$ for $\mathrm{LHF}, \mathrm{m} \mathrm{s}^{-1}$ for $\mathrm{U}, \mathrm{g} \mathrm{kg}^{-1}$ for $\mathrm{Q}_{\mathrm{a}}$ and ${ }^{\circ} \mathrm{C}$ for SST.

\begin{tabular}{llllllll}
\hline \hline Source & Days & Variable & Mean & Bias & \multicolumn{2}{c}{ SD error } & $r$ \\
\hline all & 167 & LHF & 99.8 & 0.8 & 35.8 & 6.5 & 0.83 \\
Tropics & 134 & LHF & 93.0 & -2.6 & 29.7 & 5.4 & 0.80 \\
all & 240 & $\mathrm{U}$ & 5.9 & 0.36 & 1.38 & 0.25 & 0.92 \\
Tropics & 139 & $\mathrm{U}$ & 4.6 & 0.31 & 1.07 & 0.20 & 0.87 \\
all & 240 & $\mathrm{Q}$ & 15.7 & 0.67 & 1.23 & 0.22 & 0.97 \\
Tropics & 139 & $\mathrm{Q}_{\mathrm{a}}$ & 17.7 & 1.01 & 1.11 & 0.20 & 0.85 \\
all & 279 & $\mathrm{SST}$ & 25.7 & 0.04 & 0.51 & 0.09 & 1.00 \\
Tropics & 157 & $\mathrm{SST}$ & 28.4 & 0.02 & 0.30 & 0.05 & 0.99 \\
\hline
\end{tabular}


Table 3. Regional-mean $L H F, U_{10 m}, Q_{s}-Q_{10 m}, Q_{10 m}$, and $Q_{s}$ over global oceans during 1992-93 for GSSTF2, as well as the differences of HOAPS, NCEP, and da Silva from GSSTF2.

\begin{tabular}{|c|c|c|c|c|c|}
\hline Variable & Source & $60^{\circ} \mathrm{S}-60^{\circ} \mathrm{N}$ & $20^{\circ} \mathrm{N}-60^{\circ} \mathrm{N}$ & $20^{\circ} \mathrm{S}-20^{\circ} \mathrm{N}$ & $20^{\circ} \mathrm{S}-60^{\circ} \mathrm{S}$ \\
\hline LHF & GSSTF2 & 108.2 & 104.1 & 122.1 & 94.3 \\
\hline \multirow[t]{3}{*}{$\left(\mathrm{W} \mathrm{m}^{-2}\right)$} & HOAPS & -19.7 & -14.3 & -37.4 & -2.0 \\
\hline & NCEP & -3.4 & +0.5 & +3.0 & -13.2 \\
\hline & Da Silva & -8.5 & -5.3 & +1.3 & -21.8 \\
\hline \multirow{4}{*}{$\begin{array}{l}\mathrm{U}_{10 \mathrm{~m}} \\
\left(\mathrm{~m} \mathrm{~s}^{-1}\right)\end{array}$} & GSSTF2 & 7.39 & 7.33 & 6.63 & 8.25 \\
\hline & HOAPS & -0.26 & +0.22 & -1.13 & +0.45 \\
\hline & NCEP & -0.59 & -0.27 & -1.04 & -0.26 \\
\hline & Da Silva & +0.30 & +0.84 & +0.27 & +0.04 \\
\hline \multirow{4}{*}{$\begin{array}{l}Q_{s}-Q_{10 m} \\
\left(\mathrm{~g} \mathrm{~kg}^{-1}\right)\end{array}$} & GSSTF2 & 4.14 & 3.80 & 5.10 & 3.20 \\
\hline & HOAPS & -0.48 & -0.43 & -0.70 & -0.23 \\
\hline & NCEP & -0.51 & -0.67 & -0.09 & -0.92 \\
\hline & Da Silva & -0.53 & -0.70 & -0.27 & -0.74 \\
\hline \multirow{4}{*}{$\begin{array}{l}Q_{10 \mathrm{~m}} \\
\left(\mathrm{~g} \mathrm{~kg}^{-1}\right)\end{array}$} & GSSTF2 & 12.07 & 10.19 & 16.63 & 7.81 \\
\hline & HOAPS & +0.83 & +0.71 & +1.07 & +0.59 \\
\hline & NCEP & +0.85 & +0.95 & +0.53 & +1.14 \\
\hline & Da Silva & +0.95 & +1.14 & +0.67 & +1.15 \\
\hline \multirow{4}{*}{$\begin{array}{l}Q_{S} \\
\left(\mathrm{~g} \mathrm{~kg}^{-1}\right)\end{array}$} & GSSTF2 & 16.22 & 14.01 & 21.73 & 11.01 \\
\hline & HOAPS & +0.35 & +0.28 & +0.37 & +0.36 \\
\hline & NCEP & +0.33 & +0.29 & +0.44 & +0.22 \\
\hline & Da Silva & +0.41 & +0.44 & +0.44 & +0.41 \\
\hline
\end{tabular}


Table 4. Regional-mean std dev of differences/temporal cross correlation of monthly LHF, $U_{10 m}$, $\mathrm{Q}_{\mathrm{s}}-\mathrm{Q}_{10 \mathrm{~m}}$ and $\mathrm{Q}_{10 \mathrm{~m}}$ between GSSTF2 and each of HOAPS, NCEP, and da Silva over global oceans during 1992-93.

\begin{tabular}{llllll}
\hline \hline Variable & Source & $60^{\circ} \mathrm{S}-60^{\circ} \mathrm{N}$ & $20^{\circ} \mathrm{N}-60^{\circ} \mathrm{N}$ & $20^{\circ} \mathrm{S}-20^{\circ} \mathrm{N}$ & $20^{\circ} \mathrm{S}-60^{\circ} \mathrm{S}$ \\
\hline $\mathrm{LHF}$ & HOAPS & $16.8 / 0.81$ & $18.9 / 0.87$ & $16.9 / 0.83$ & $15.6 / 0.77$ \\
$\left(\mathrm{~W} \mathrm{~m}{ }^{-2}\right)$ & NCEP & $18.3 / 0.78$ & $17.4 / 0.88$ & $23.0 / 0.69$ & $13.4 / 0.84$ \\
& Da Silva & $25.7 / 0.51$ & $25.1 / 0.73$ & $27.0 / 0.54$ & $24.4 / 0.35$ \\
\hline $\mathrm{U}_{10 \mathrm{~m}}$ & HOAPS & $0.67 / 0.85$ & $0.79 / 0.87$ & $0.61 / 0.87$ & $0.67 / 0.81$ \\
$\left(\mathrm{~m} \mathrm{~s}^{-1}\right)$ & NCEP & $0.63 / 0.84$ & $0.59 / 0.91$ & $0.71 / 0.80$ & $0.56 / 0.86$ \\
& Da Silva & $1.01 / 0.55$ & $0.98 / 0.71$ & $0.93 / 0.64$ & $1.12 / 0.35$ \\
\hline $\mathrm{Q}_{5}-\mathrm{Q}_{10 \mathrm{~m}}$ & HOAPS & $0.52 / 0.77$ & $0.57 / 0.81$ & $0.55 / 0.81$ & $0.45 / 0.70$ \\
$\left(\mathrm{~g} \mathrm{~kg}^{-1}\right)$ & NCEP & $0.71 / 0.50$ & $0.69 / 0.70$ & $0.93 / 0.27$ & $0.47 / 0.66$ \\
& Da Silva & $0.75 / 0.34$ & $0.78 / 0.59$ & $0.80 / 0.31$ & $0.67 / 0.24$ \\
\hline $\mathrm{Q}_{10 \mathrm{~m}}$ & HOAPS & $0.38 / 0.97$ & $0.48 / 0.98$ & $0.37 / 0.97$ & $0.35 / 0.96$ \\
$\left(\mathrm{~g} \mathrm{~kg}^{-1}\right)$ & NCEP & $0.70 / 0.85$ & $0.67 / 0.96$ & $0.92 / 0.71$ & $0.46 / 0.95$ \\
& Da Silva & $0.83 / 0.81$ & $0.82 / 0.94$ & $0.88 / 0.78$ & $0.77 / 0.79$ \\
\hline
\end{tabular}




\section{TABLE CAPTIONS}

Table 1. Times and locations of nine field experiments conducted by the NOAA/ETL research ships.

Table 2. Comparison of daily LHF, surface wind speed $(U)$, surface air specific humidity $\left(Q_{a}\right)$, and SST of GSSTF2 with those of all nine field experiments and five tropical experiments with large samples. The mean is ship-observed values averaged over collocated days, positive bias indicates larger GSSTF2, SD error is std dev of differences, and $r$ is correlation coefficient. Units are $\mathrm{W} \mathrm{m}^{-2}$ for $\mathrm{LHF}, \mathrm{m} \mathrm{s}^{-1}$ for $\mathrm{U}, \mathrm{g} \mathrm{kg}^{-1}$ for $\mathrm{Q}_{\mathrm{a}}$, and ${ }^{\circ} \mathrm{C}$ for SST.

Table 3. Regional-mean LHF, $U_{10 m}, Q_{s}-Q_{10 m}, Q_{10 m}$, and $Q_{s}$ over global oceans during 1992-93 for GSSTF2, as well as the differences of HOAPS, NCEP, and da Silva from GSSTF2.

Table 4. Regional-mean std dev of differences/temporal cross correlation of monthly LHF, $U_{10 m}$, $\mathrm{Q}_{\mathrm{s}}-\mathrm{Q}_{10 \mathrm{~m}}$ and $\mathrm{Q}_{10 \mathrm{~m}}$ between GSSTF2 and each of HOAPS, NCEP, and da Silva over global oceans during 1992-93. 


\section{FIGURE CAPTIONS}

Fig. 1. GSSTF2 daily (a) latent heat fluxes, (b) surface winds, and (c) surface air specific humidity versus those of nine field experiments. $\mathrm{C}$ is for COARE, $\mathrm{F}$ for FASTEX, and $\mathrm{X}$ for other experiments.

Fig. 2. The 10-m wind speed averaged over 1992-93 for (a) GSSTF2, and differences of (b) HOAPS, (c) NCEP, and (d) da Silva from GSSTF2. Only collocated monthly valid data from all four datasets are used.

Fig.3. Standard deviations of differences (left) and temporal cross correlation (right) of monthly 10-m wind speeds between GSSTF2 and each of $(a, b)$ HOAPS, (c, d) NCEP, and (e, f) da Silva during 1992-93.

Fig. 4. Same as Fig. 2, except for 10-m specific humidity.

Fig. 5. Same as Fig. 2, except for sea-10m humidity differences.

Fig. 6. Same as Fig. 3, except for sea-10m humidity differences.

Fig. 7. Same as Fig. 2, except for latent heat fluxes.

Fig. 8. Same as Fig. 3, except for latent heat fluxes. 

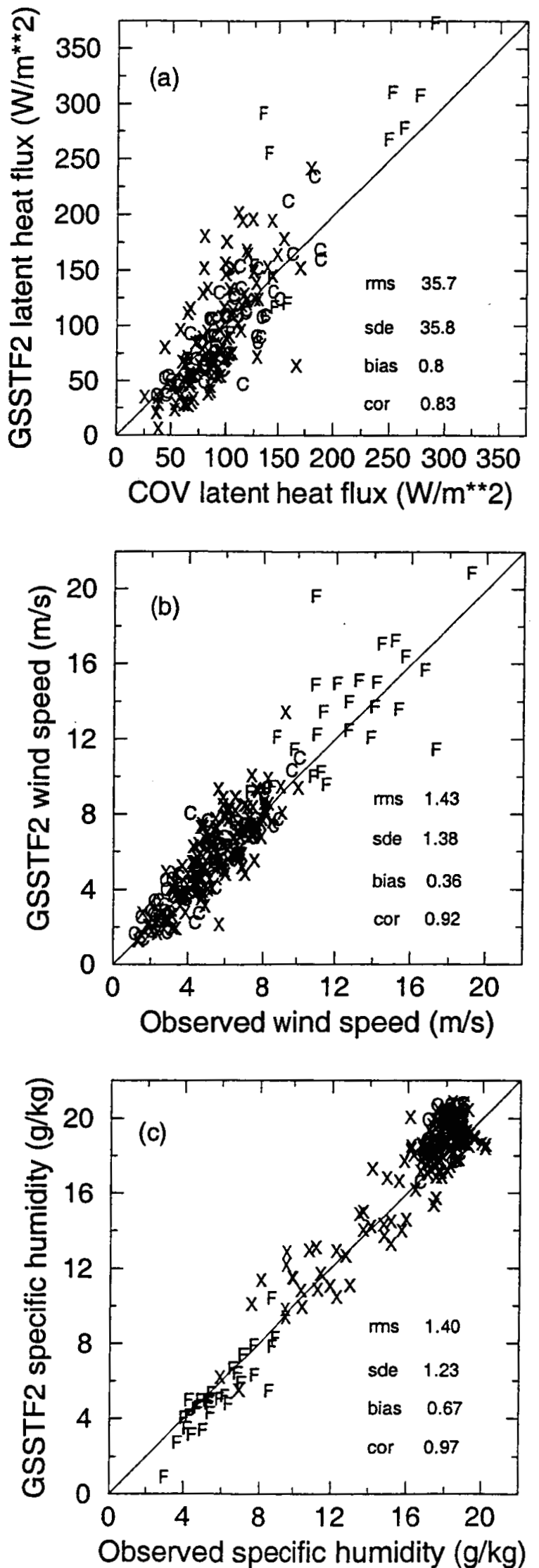


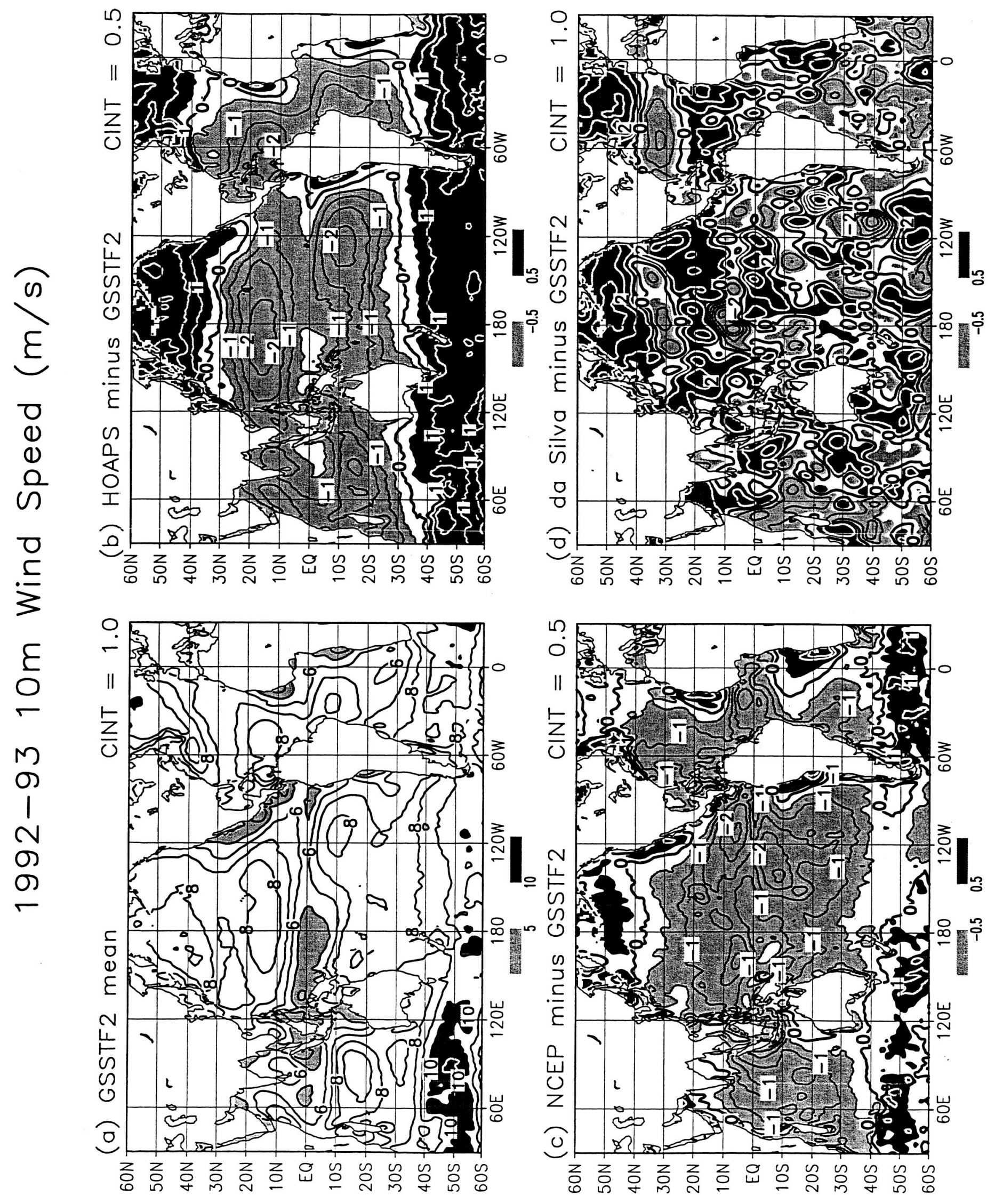


1992-1993 Monthly SDD (m/s): U10m

(a) HOAPS vs GSSTF2

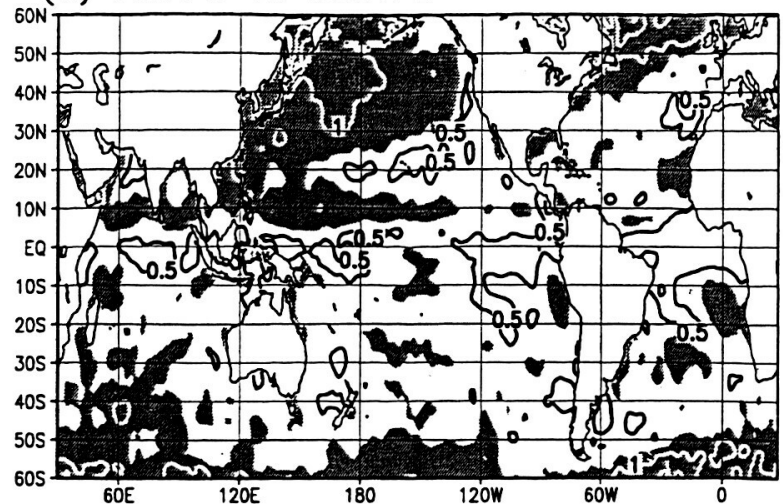

(c) NCEP vs GSSTF2

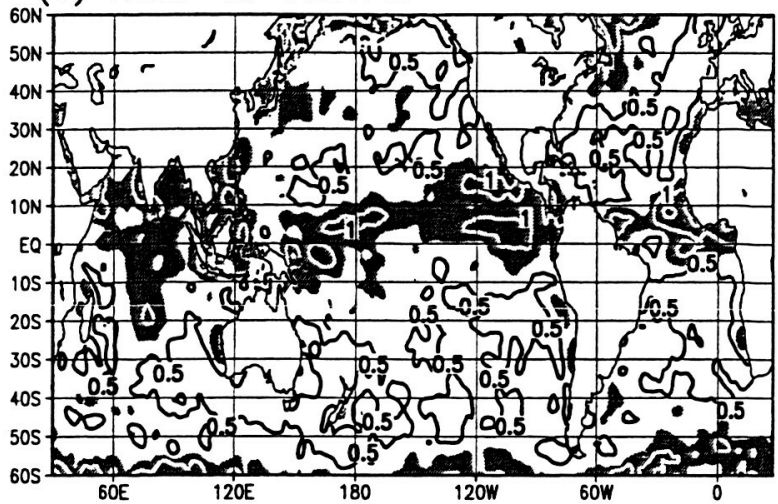

(e) da Silva vs GSSTF2

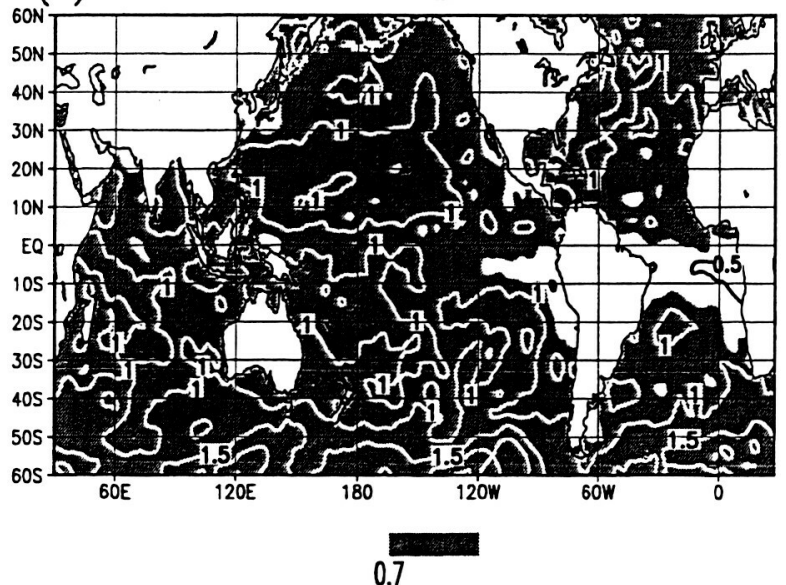

1992-1993 Monthly Correlation*10: U10m

(b) HOAPS vs GSSTF2

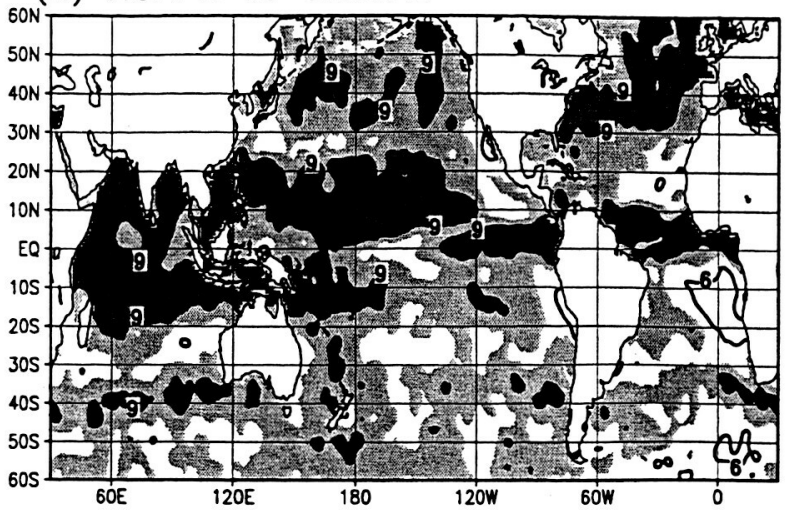

(d) NCEP vs GSSTF2
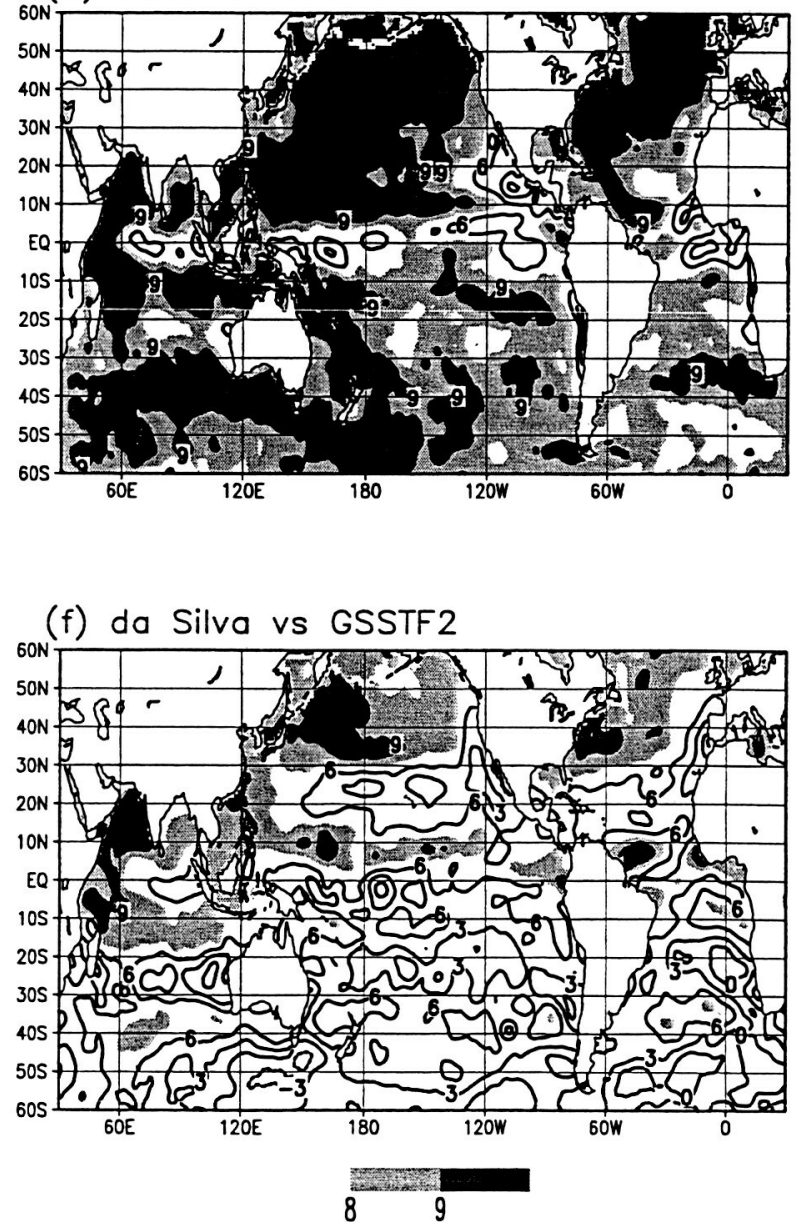

Fig. 3 


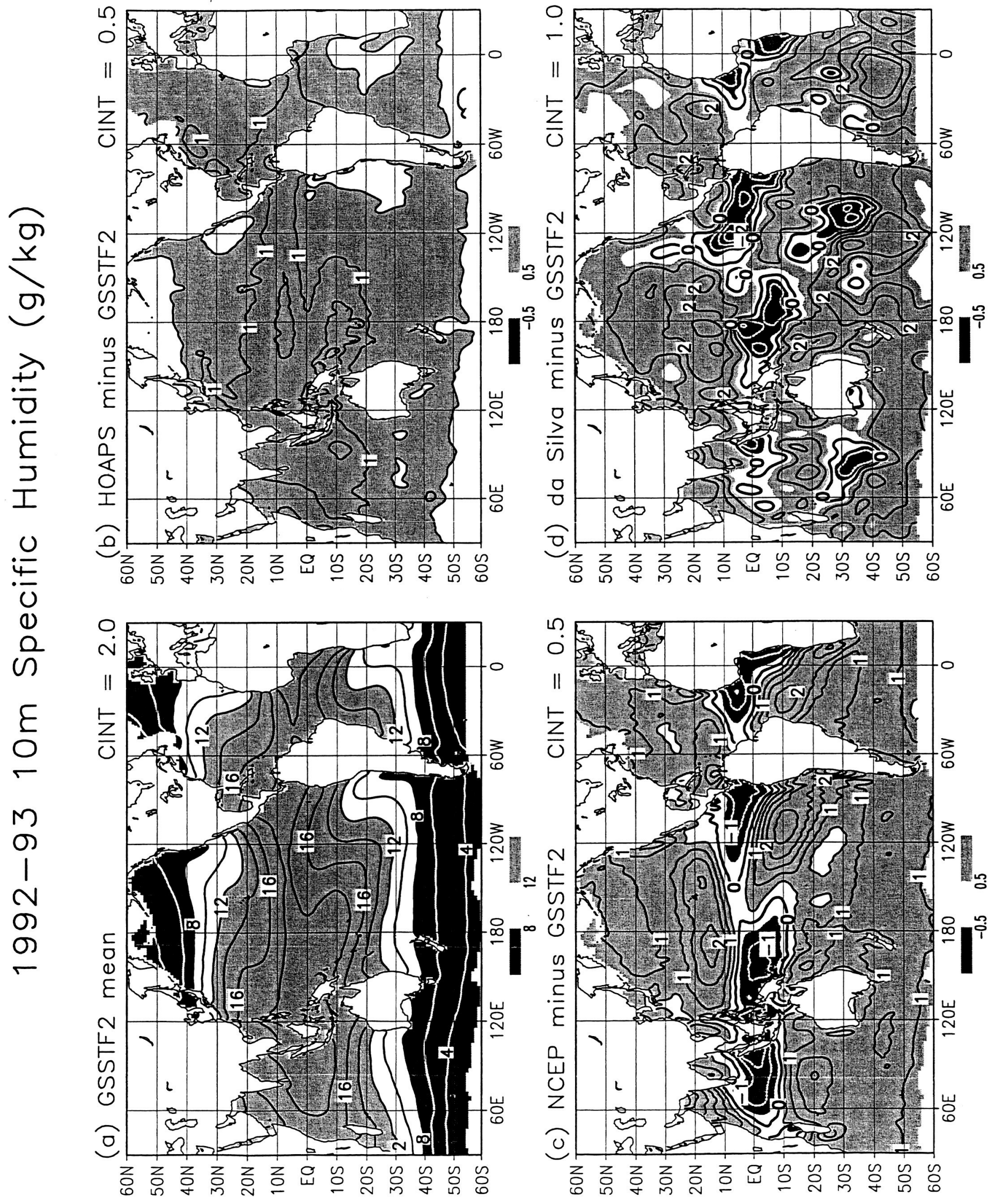

$*$ of 

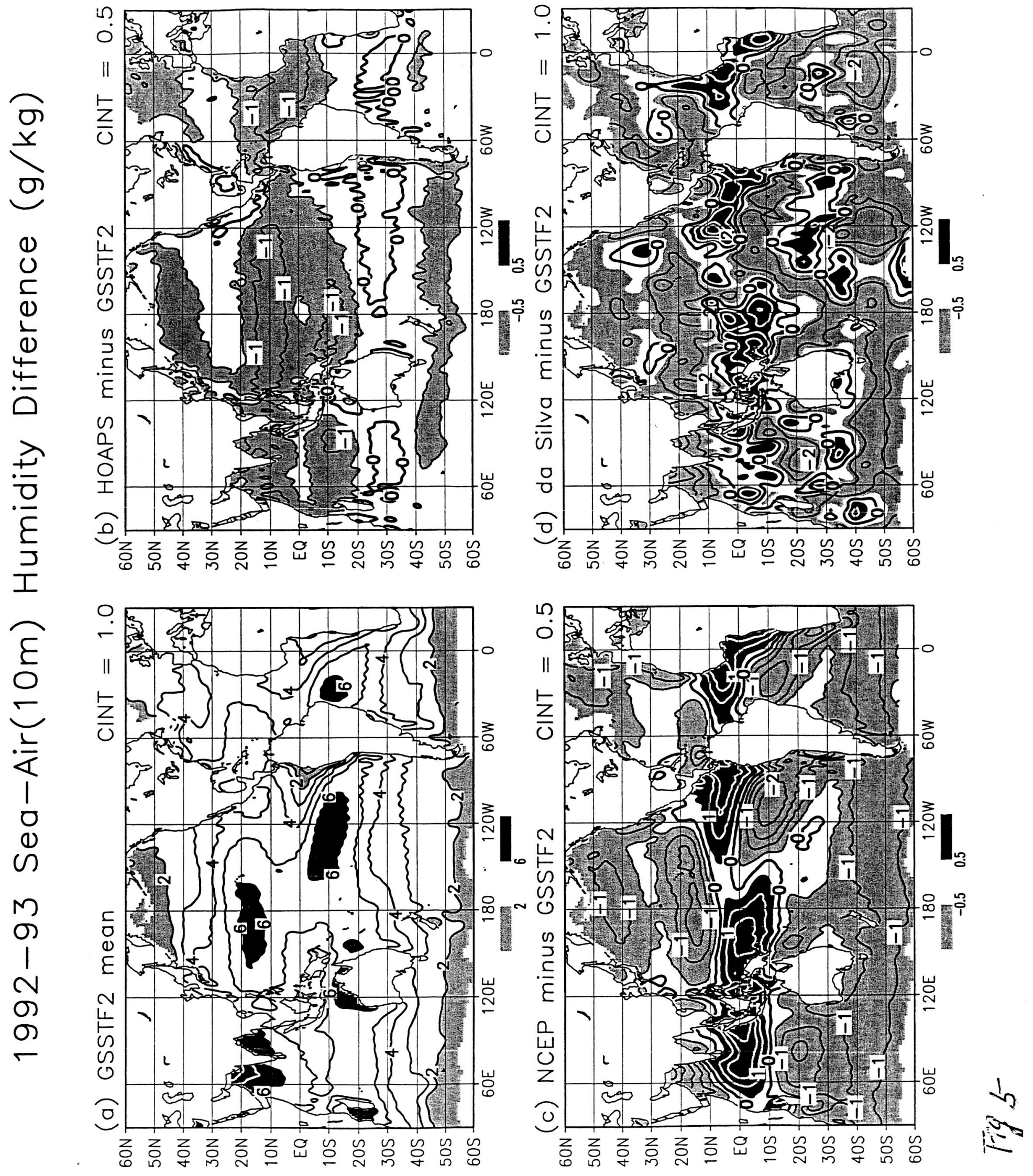
1992-1993 Monthly SDD (g/kg): Qs-Q10m

(a) HOAPS vs GSSTF2

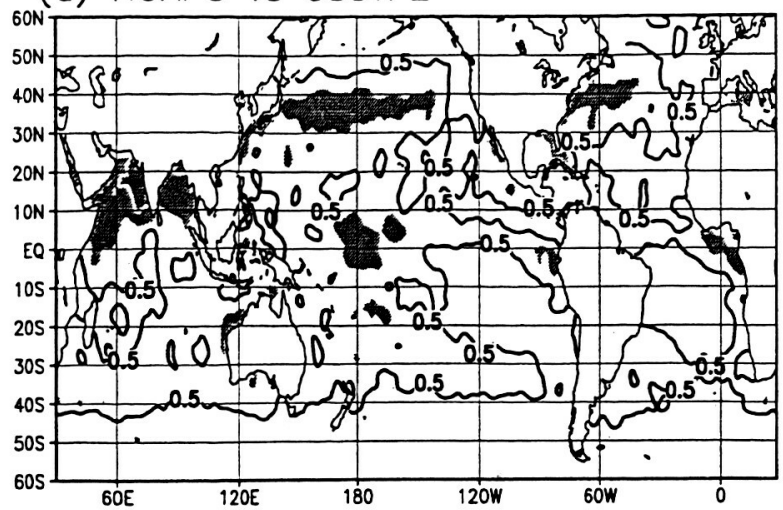

(c) NCEP vs GSSTF2

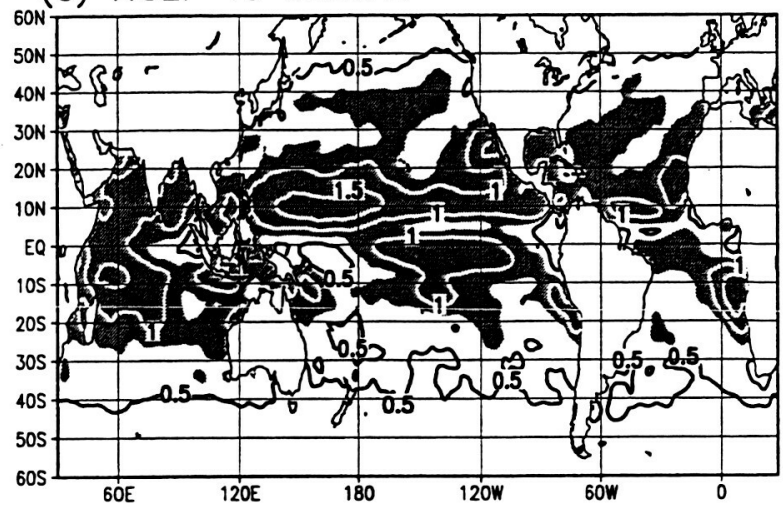

(e) da Silva vs GSSTF2

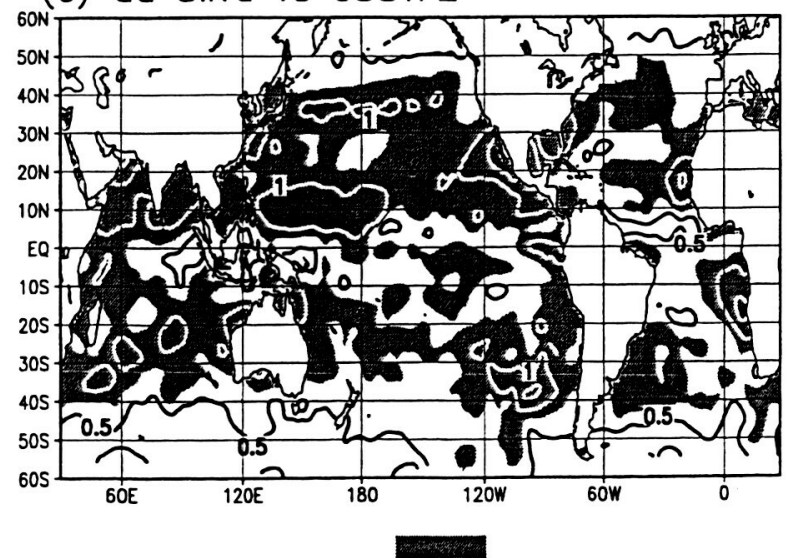

0.7
1992-1993 Monthly Correlation*10: Qs-Q10m

(b) HOAPS vs GSSTF2

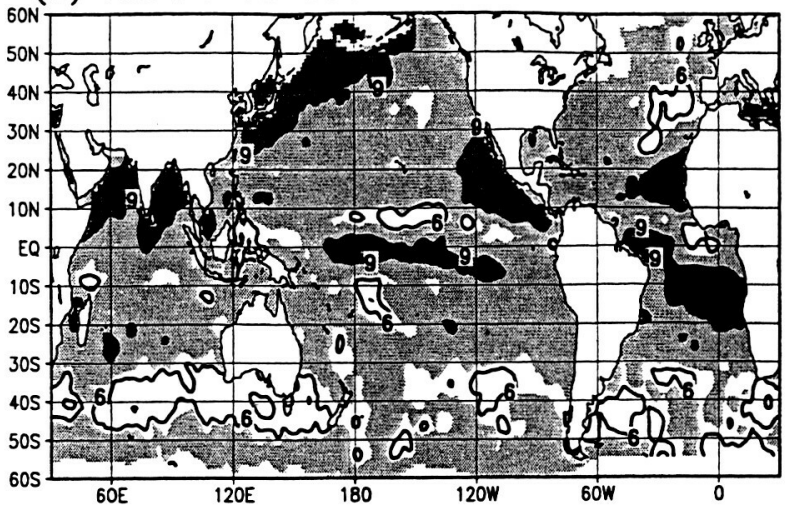

(d) NCEP vs GSSTF2

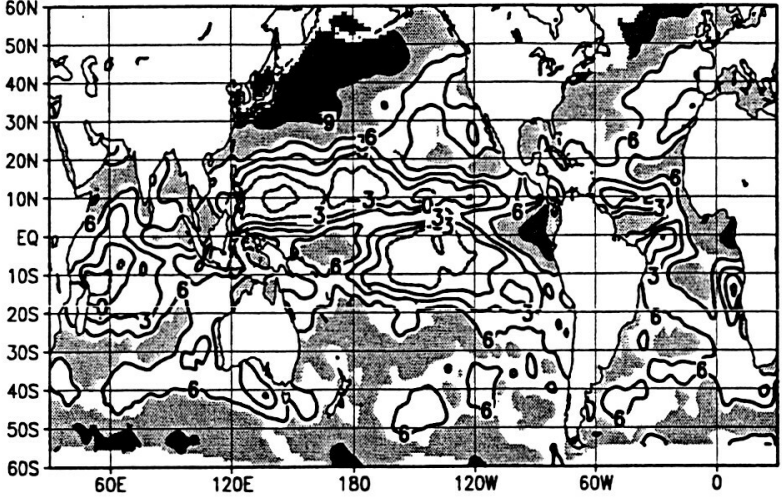

(f) da Silva vs GSSTF2

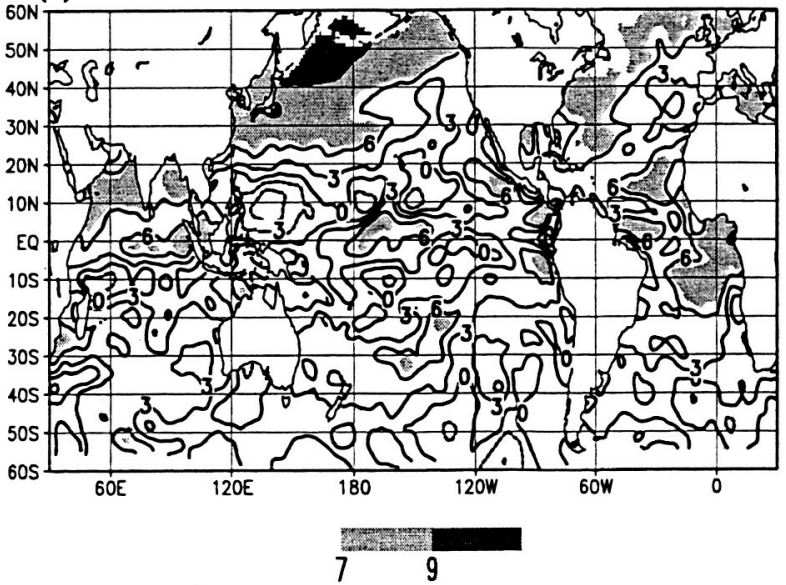

Fig.6 

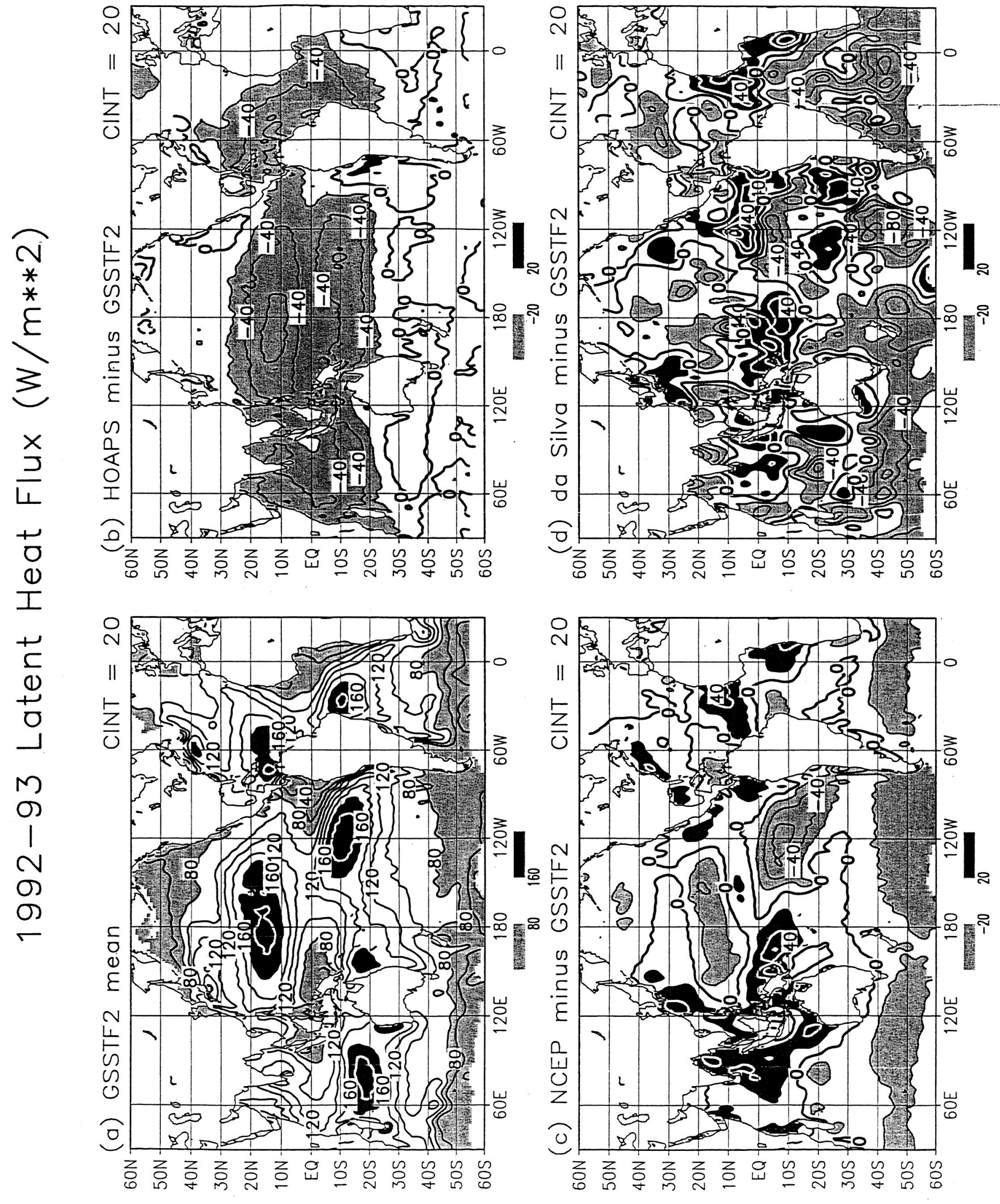
1992-1993 Monthly SDD (W/m^2): LHF

(a) HOAPS vS GSSTF2

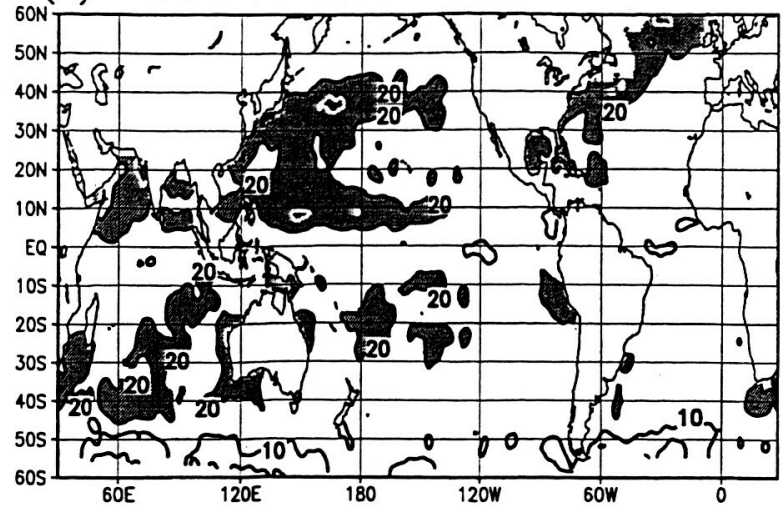

(c) NCEP vs GSSTF2

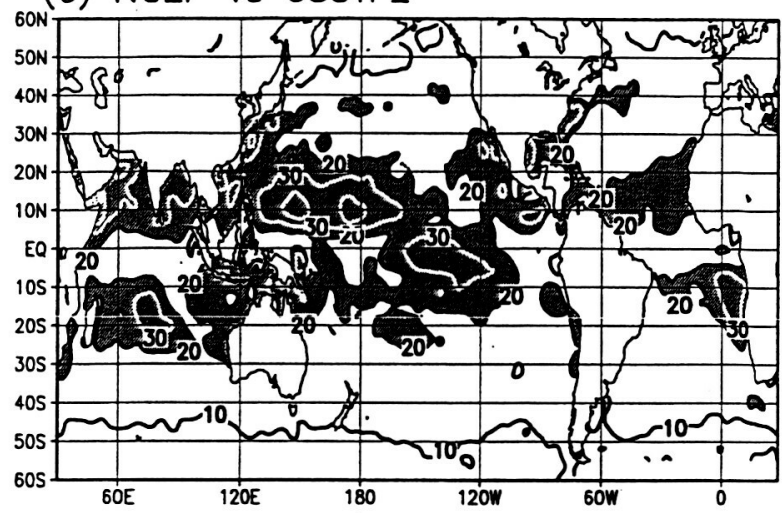

(e) da Silva vs GSSTF2

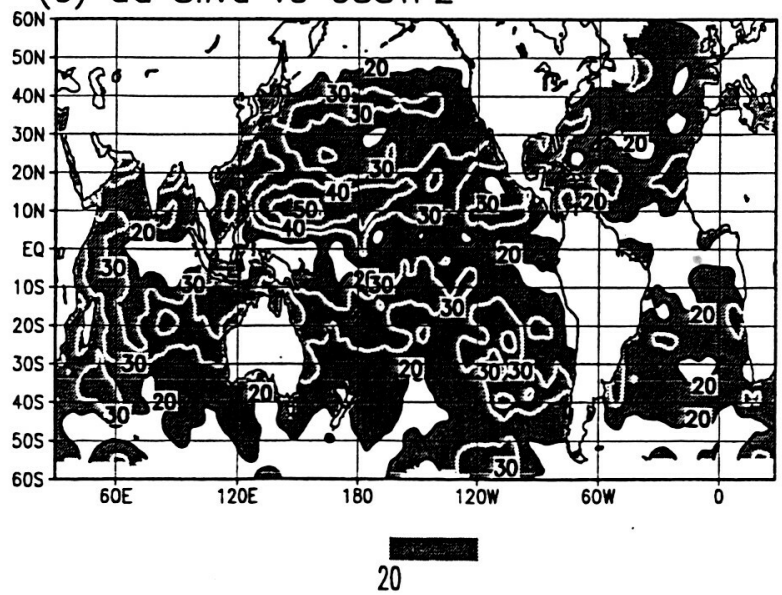

1992-1993 Monthly Correlation*10: LHF

(b) HOAPS vs GSSTF2

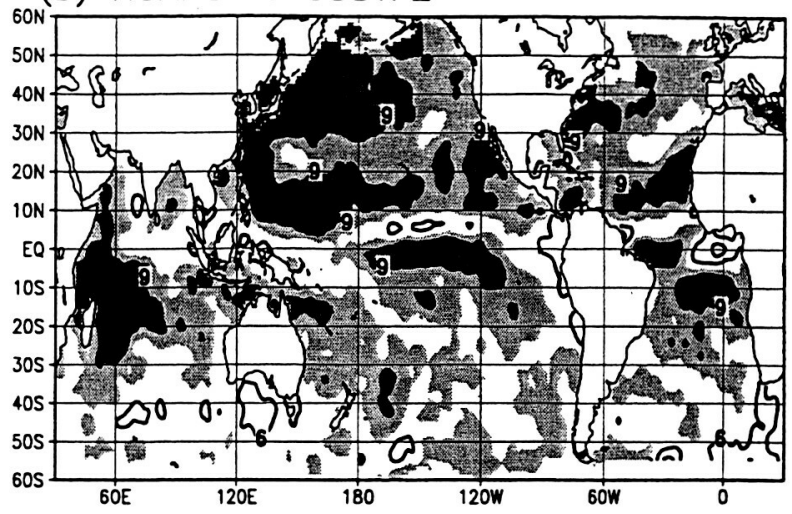

(d) NCEP vs GSSTF2

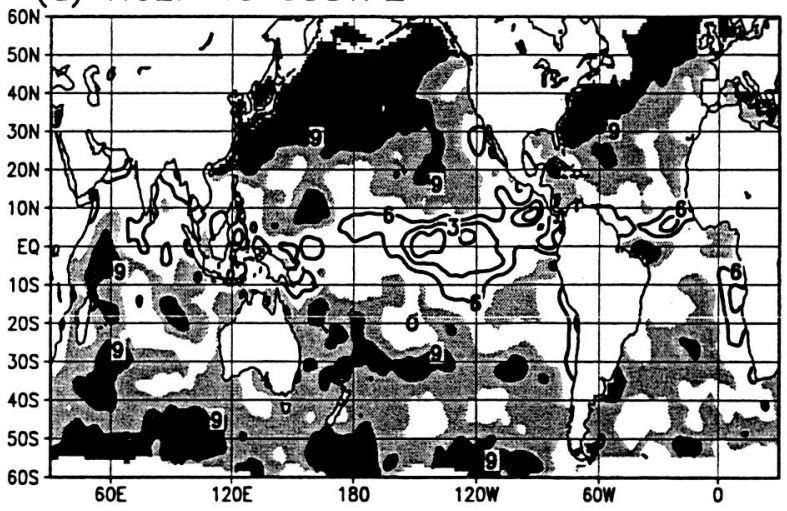

(f) da Silva vs GSSTF2

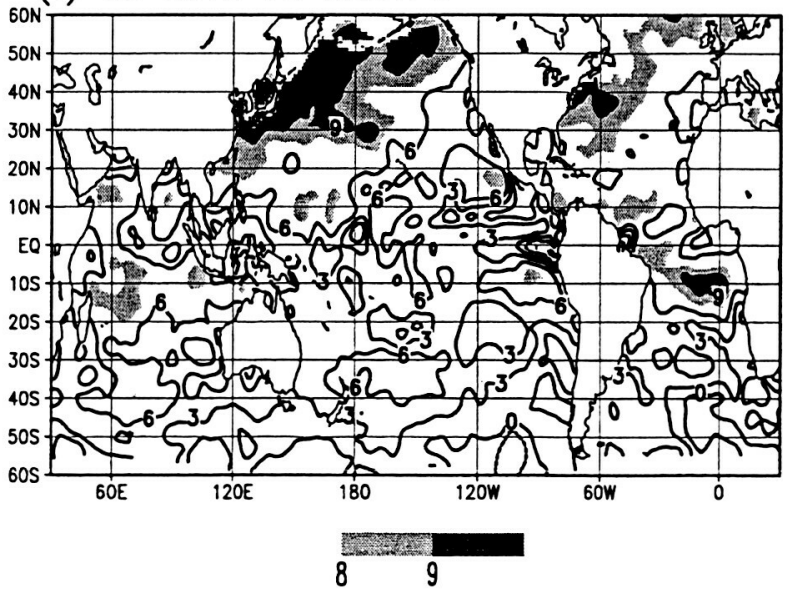

Fig.8 